Article

\title{
Spatial-Temporal Evolution and Factor Decomposition for Ecological Pressure of Carbon Footprint in the One Belt and One Road
}

\author{
Qipeng Sun ${ }^{1,2}$, Yafang Geng ${ }^{1,2, *}$, Fei Ma ${ }^{1,2}$, Chao Wang ${ }^{1}$, Bo Wang ${ }^{1}$, Xiu Wang ${ }^{1,2}$ and \\ Wenlin Wang ${ }^{1,2}$ \\ 1 School of Economics and Management, Chang'an University, Xi'an 710064, China; sunqip@chd.edu.cn (Q.S.); \\ mafeixa@chd.edu.cn (F.M.); 2016123083@chd.edu.cn (C.W.); 2016123085@chd.edu.cn (B.W.); \\ 2016123017@chd.edu.cn (X.W.); 2016123084@chd.edu.cn (W.W.) \\ 2 Integrated Transportation Economics and Management Research Center, Chang'an University, \\ Xi'an 710064, China \\ * Correspondence: 2016123039@chd.edu.cn; Tel.: +86-29-8233-8932
}

Received: 19 July 2018; Accepted: 24 August 2018; Published: 31 August 2018

\begin{abstract}
Low-carbon and green development is important to promote the sustainable economic and social development of countries along the One Belt and One Road. These countries have distinct differences in their ability to withstand carbon emission pressures and their driving factors, due to different stages of development and economic characteristics. This paper presents a model of ecological pressure of the carbon footprint in energy consumption $\left(E P_{c f e c}\right)$, defined by three states: light, balanced, and heavy pressure. The $E P_{c f e c}$ was calculated from data on 56 countries along the One Belt and One Road from 1994-2014, and analysis of the data's temporal and spatial evolutionary rules was conducted. Furthermore, we used the LMDI method to extract the driving forces of $E P_{c f e c}$ and evaluated the contribution of these factors to the overall region and seven sub-regions. The results showed that $E P_{c f e c}$ growth slowed over time, with the value of $E P_{c f e c}$ reaching 3190.51 in 2014. Resource-rich countries have a greater value of $E P_{c f e c}$ and are mainly distributed in parts of West Asia, North Africa, and Southeast Asia. The per capita export of goods and services, and the population density on productive land contribute to ecological pressure on the carbon footprint. Energy structure, the influence of international trade on GDP, and energy intensity exerted an inhibitory effect on the ecological pressure of the carbon footprint. This paper proposes mitigation measures for optimizing energy structure, improving energy efficiency, developing low energy consumption, and promoting green international trade. Our results provide support for countries along the One Belt and One Road to mitigate ecological pressures resulting from their carbon footprint.
\end{abstract}

Keywords: ecological pressure; energy consumption; spatial-temporal evolution; LMDI

\section{Introduction}

Actively responding to global climate change has become an urgent issue for all countries [1]. In December 2015, 196 countries signed the Paris Agreement to jointly promote a plan to curb global warming [2]. China is the first developing country to propose energy-saving and emission reduction targets. It has committed itself to reducing carbon emission intensity in 2020 to $55-60 \%$ of the levels in 2005 [3]. In November 2014, the Chinese government strived to realize the target of decreasing carbon emission as soon as possible $[4,5]$ in accordance with the China-US Joint Statement on Climate Change. Many countries have also successively promulgated their own low-carbon action plans. At present, the situation of carbon emissions is still very serious, and is mainly driven by economic sectors with high energy consumption. Global greenhouse gas emission data show that in 2015, global carbon 
emissions were 4.91 billion tons. The contributions of various economic sectors were as follows: electricity production: $29 \%$, transportation: $27 \%$, industry: $21 \%$, commercial and residential: $12 \%$, and agriculture: $9 \%$ [6]. The trend of high energy consumption and high emissions has caused tremendous ecological pressure in all countries. Economic activity is one of the most important factors for change in carbon emissions [7]. Decomposing the contribution of various economic development factors to changes in carbon emissions can provide an effective basis for formulating emission reduction policies, and coordinating the balance between economic growth and ecological protection [8].

The "Silk Road Economic Belt" and the "21st Century Maritime Silk Road" (One Belt and One Road) are open international initiatives proposed by the Chinese government. Their goal is to achieve shared benefits for all the countries along the route [9-11]. Green development is an inevitable choice for the countries along the One Belt and One Road, and an objective requirement for the development of the world economy. At present, most of the countries along the One Belt and One Road are developing countries. The development stage and economic characteristics of the various countries are quite different. In 2016, the amount of carbon emissions in the region accounted for $56.1 \%$ of global carbon emissions [12], and most of the countries had not established clear emission reduction targets and action paths. Therefore, selecting countries along the One Belt and One Road as targets to explore the issue of carbon emission pressures is of great importance for the global response to climate change issues. It is also an important means for the countries along the route to seek more feasible and effective emission reduction pathways and achieve sustainable development [13].

In recent years, many researchers have used carbon footprint to assess the combined environmental impacts of carbon emissions from human economic activities [14,15]. In 1992, Rees [16] and Wackernagel and Rees [17,18] proposed the concept of the ecological footprint. On this basis, Thomas Wiedmann and Jan Minx [19] proposed the concept of the carbon footprint, which is used to measure the total amount of carbon dioxide emissions directly or indirectly caused by an activity, or the total amount of carbon dioxide accumulated in the product life cycle. At the same time, some scholars have defined the carbon footprint as the productive land area needed to absorb carbon emissions, indicating the ecological footprint of carbon emissions [20]. Since then, others have analyzed carbon footprints from perspectives such as households [21], products [22,23], industries, and sectors [24,25], cities [26], countries [27], and so forth. Most of the research focuses on the industrial and regional levels. Brown et al. [28] took the example of 100 major metropolitan areas in the United States to analyze the carbon emissions from energy consumption in the transportation sector and the construction industry. Hertwich [29] analyzed the carbon footprint of 73 countries and 14 clustered regions. Based on energy consumption data, Chuai and Li [30] studied the temporal and spatial changes in the carbon footprint of six regions in Northeast China, North China, and East China, and concluded that the carbon emissions, carbon footprint, and carbon footprint intensity in East China were significantly higher than those in the other regions. Chen [31] used the Stochastic Impacts by Regression on Population, Affluence and Technology (STIRPAT) model and the partial least squares model to assess Beijing's carbon footprint of energy consumption from the perspectives of population, urbanization, and technology, and analyzed the impact of different factors on the carbon footprint.

Existing studies tend to focus on the carbon footprint itself and do not correlate the carbon footprint with other environmental factors. The introduction of ecological pressure into carbon footprint research can intuitively reflect the impact of carbon emissions on the ecological environment, which is an issue of notable interest. There is little relevant literature at present, and those papers that do exist are usually characterized by carbon footprint ecological pressure [32,33]. In order to seek the source of carbon footprint ecological pressure, it is necessary to decompose the contribution of its driving factors into the various ecological pressure affecting the carbon footprint [34]. Based on studies of the ecological pressure of the carbon footprint of energy consumption, Zhang et al. used logarithmic mean divisia index (LMDI) to decompose the driving forces of different factors. They found that the promotion of economic factors outweighed the inhibitory effects of other factors, and that the ecological pressure brought about by economic development was the most prominent factor [35]. 
At present, factor decomposition is mostly used in the study of carbon emission driving factors, and a flood of related research has been undertaken in this area since the mid-1980s. There are four main types of methods used. The first category comprises those that focus on identifying the factors affecting carbon emissions through structural decomposition techniques (SDA) under the input-output analysis framework, combined with input-output tables and models [36]. Feng [37] found that the economic growth of the United States during 1997-2007 was the key factor driving the increase of carbon emissions. The change in the energy structure over this period was an important factor in restraining carbon emission growth. Such studies often rely on input-output tables for non-continuous intertemporal analysis, and the types of impact factors are single, which makes it difficult to examine the impact of multiple types of socioeconomic factors. The second category uses the Computable General Equilibrium (CGE) model and scenario analysis to calculate the impact of different socioeconomic factors and their combinations on carbon emissions, in accordance with general equilibrium conditions. This type of research is also dependent on input-output tables, however it is not straightforward to uncover the underlying continuum of a time series [38,39]. The third category comprises the use of econometric models to study the impact of various factors on carbon emissions. There are many such methods, but all of them can reveal only statistical laws, not the intrinsic driving factors [40,41]. The fourth category uses the Kaya identity, along with extensions and improvements. They use factorial decomposition techniques (IDA) to calculate the contribution of different factors. This type of method has a variety of decomposition forms and can be selected based on research needs [42-45]. The logarithmic mean Divisia index (LMDI) method is such a method. It was proposed by Ang et al. in 1998, who deduced its mathematical properties, as well as summarizing a large number of applications of IDA models. Its advantages include using of diverse forms, simple calculations, and the ability to find intrinsic driving factors [46-49]. The method is used in many research fields, such as for the decomposition of energy consumption or carbon emission factors. For example, Vinuya et al. $[50,51]$ used the LMDI decomposition model to find that economic and population growth is the largest factor driving carbon emissions. The increase in energy use efficiency and the decline in energy intensity can effectively restrain the increase in carbon emissions due to the impact of GDP and population increase. Ma and Stern improved the IDA model and used the LMDI method to decompose the energy intensity changes from 1980-2003, confirming that technological progress is the most important factor in reducing energy intensity [52]. Zhang et al. used the LMDI method to find that the rapid growth of carbon emissions in China's power generation industry is mainly due to the use of coal, and energy efficiency is also an important contributor [53]. Inglesi-Lotz applied LMDI to study the main factors affecting the changes in $\mathrm{CO}_{2}$ emissions in South Africa. They found that energy intensity had a negative impact on $\mathrm{CO}_{2}$ emissions during 2008-2014 [54]. The use of LMDI by Kopidou et al. showed that the two main drivers of industrial $\mathrm{CO}_{2}$ emissions and employment are economic growth and resource intensity, and that the optimization of the energy structure is conducive to national emission reduction [55].

The One Belt and One Road is a shared, win-win, open economic and trade cooperation initiative, covering many countries and regions. At present, most of the research on One Belt and One Road focuses on strategic significance, institutional design [11,56], and capacity cooperation [57-59]. The primary focus has been how to promote the economic development of each country. However, there are several studies on the green and coordinated development of the international regional economy. The related literature focuses on the OECD [60,61], East Asia, ASEAN [62,63], the European Union and its sub-regions [17,64], and a few international regions, meaning less attention is paid to the coordinated development of the regional economy and environment in the One Belt and One Road area. In fact, most of the countries along the "One Belt and One Road" are developing or underdeveloped countries, many of which are not concerned with the problem of low carbon and emission reduction. In addition, the development stages and economic characteristics of the countries along the route are quite different. Therefore, selecting countries along the One Belt and One Road as the target 
and exploring the carbon footprint ecological pressures of those countries is of great significance to sustainable development; it can also contribute to global emission reduction targets.

In summary, previous research has mainly focused on the measurement and causes of carbon emissions and carbon footprints. There has been little research on ecological pressure caused by carbon footprints, and it does not directly reflect the impact of carbon emissions on the ecological environment.

The LMDI method has been widely used in carbon emission and carbon footprint research. In previous work looking at causal factors, the choice of factors was not varied, with the main focus always being the country. Explanations of changes to ecological pressure resulting from the global carbon footprint were insufficient. In addition, the scope of the countries included was relatively limited, and the differences in economic characteristics and resource endowments among countries are relatively small, which limits the applicability of the research. By selecting countries along the One Belt and One Road with large differences in economic characteristics and resource endowments-based on an ecological-pressure-based model of energy consumption and the carbon footprint-we adopted the LMDI decomposition method to introduce the driving factors that reflect the links between the global carbon footprint and ecological pressure. Factors include the per capita export goods and services trade volume, and the influence of international trade on GDP. Our approach makes the study of the ecological pressures arising from energy consumption as measured by the carbon footprint more straightforward.

The rest of the paper is organized as follows: In Section 2, the concepts of the energy consumption carbon footprint $(C F E C)$ and carbon footprint ecological pressure $\left(E P_{c f e c}\right)$ are proposed, and the measurement and factor decomposition model of $E P_{c f f c}$ are explained and constructed. Section 3 introduces the research scope, data sources, and regional divisions. Section 4 analyzes the calculation results and spatial evolution of $E P_{c f e c}$ from 1994-2014, and uses the LMDI method to decompose $E P_{c f e c}$. The conclusions and recommendations are given in Section 5.

\section{Methodology}

\subsection{Carbon Footprint Measurement Model of Energy Consumption}

The carbon footprint is a quantified value that measures carbon emissions. It is based the concept of an ecological footprint and can directly measure the response of a natural system to carbon emissions from human activities [65]. In this paper, we use a measure of carbon footprint based on energy consumption, mainly related to coal, oil, and natural gas. The carbon footprint is measured using the productive land area needed to store energy consumption (see Equation (1)). According to the data provided by the IPCC (2006), productive land includes forests, grasslands, arable land, gardens, and other agricultural lands, of which forest and grassland carbon reserves account for $93 \%$ of the total productive land [66]:

$$
C F E C=\sum_{i=1}^{3}\left(Q_{i} \times E F_{i}\right) / \beta \quad(i=1,2,3)
$$

where CFEC refers to the carbon footprint of energy consumption $\left(\mathrm{hm}^{2}\right) ; Q_{i}$ is the energy consumption of the $i$ th energy $(\mathrm{t})$; and $E F_{i}$ is the energy carbon emission factor $(\mathrm{t} / \mathrm{tec})$, for which the study takes the average from several agencies, such as the EIA, as shown in Table 1 [67-69]. $\beta$ is the conversion coefficient for converting carbon emissions into land area, for which the adopted WWF's value is $6.49 \mathrm{t} / \mathrm{hm}^{2}[70]$. 
Table 1. Carbon emission factors of various agencies.

\begin{tabular}{cccc}
\hline Research Institute & Coal & Oil & Natural Gas \\
\hline EIA & 0.702 & 0.478 & 0.389 \\
IEEJ & 0.756 & 0.586 & 0.449 \\
Energy Research Institute National Development and Reform Commission & 0.747 & 0.582 & 0.443 \\
Mean & 0.735 & 0.549 & 0.427 \\
\hline
\end{tabular}

\subsection{The Econometric Model of $E P_{c f e c}$}

The ecological pressure of the carbon footprint in energy consumption $\left(E P_{c f e c}\right)$ refers to the pressure of carbon emissions on the natural ecosystem and is the ratio of the carbon footprint to productive land area. The calculation is as follows:

$$
E P_{c f e c}=\frac{C F E C}{S_{f}+S_{a}+S_{c}+S_{p}}
$$

where CFEC is the carbon footprint as described above; and $S_{f}, S_{a}, S_{c}$, and $S_{p}$ refer to the area of forest, cultivated land, permanent cropland, and permanent ranching land, respectively, with the unit $\mathrm{hm}^{2}$.

When $E P_{c f e c} \in(0,1)$, the productive land can fully absorb the carbon emissions resulting from energy consumption, and the carbon emissions, therefore, exert little pressure on the ecological environment. The smaller the value of $E P_{c f e c}$, the lower the ecological pressure. This is termed the light pressure state.

When $E P_{c f e c}=1$, the carbon emissions generated by energy consumption are equal to those of being absorbed by productive land; that is, the productive land has reached its capacity to absorb the carbon emissions from energy consumption. This is the balanced state.

When $E P_{c f e c} \in(1,+\infty)$, the productive land cannot fully absorb the carbon emissions, and the ecological environment faces a large amount of pressure from carbon storage. The larger the value of $E P_{c f e c}$, the greater the ecological pressure on the carbon footprint. At this point, it is in the high pressure state.

A schematic diagram of the three pressure states is shown in Figure 1.

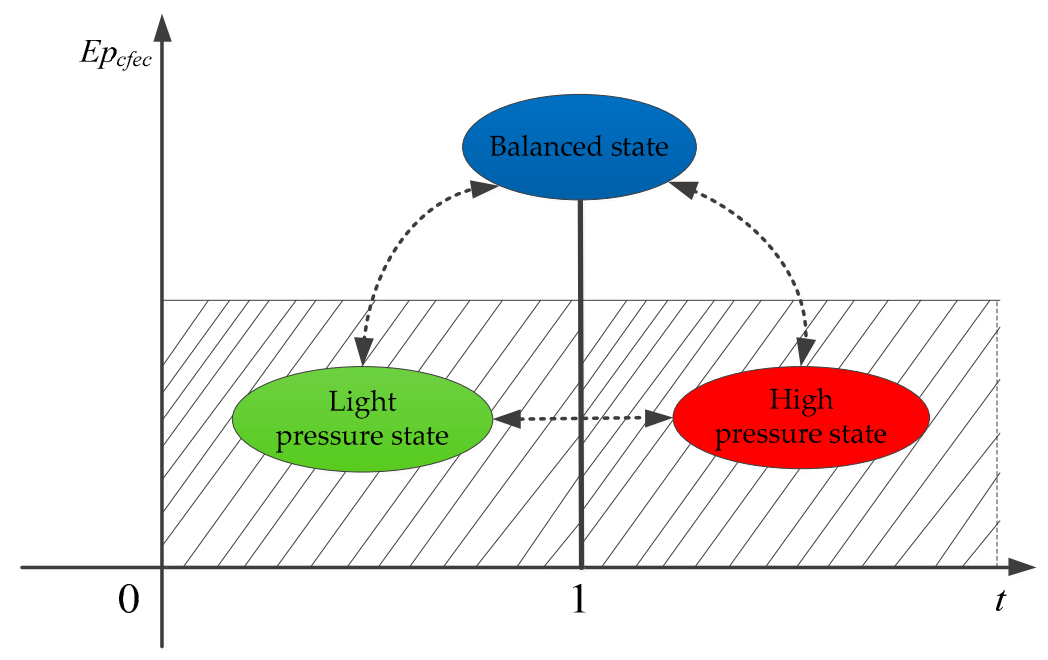

Figure 1. Pressure state diagram.

\subsection{Decomposition Method of $E P_{c f e c}$}

The paper applies the LMDI method to the decomposition of ecological pressure factors influencing the carbon footprint. The model introduces two factors related to the $E P_{c f f c}$-the influence 
of international trade on GDP, per capita exports of goods and service trade-reflecting linked changes in the ecological pressure between countries. We decomposed the driving factors into five categories: energy structure, energy intensity, the influence of international trade on GDP, per capita export goods and services trade volume, and population intensity of productive land (see Equation (3)). The variables are defined in Table 2.

$$
E P_{\text {cfec },}=\frac{C}{Q} \times \frac{Q}{E} \times \frac{E}{Y} \times \frac{Y}{E X P} \times \frac{E X P}{P O P} \times \frac{P O P}{H} \times \varepsilon=E F \times E S \times E I \times Y E \times E P \times P H \times \varepsilon,
$$

where $C$ is the carbon emission of non-renewable energy as described above; $Q$ is the consumption of non-renewable energy; $E$ is the total energy consumption including renewable energy and non-renewable energy; $Y$ is the gross domestic product; EXP is exports of goods and services; $P O P$ is the total population of every country; $H$ is the productive land area; $\varepsilon$ means coefficient; $E F$ means carbon emission intensity, which is the ith energy carbon emission coefficient; ES means the energy structure that is the proportion of non-renewable energy in the total energy consumption; EI means the energy intensity that is the ratio of total energy consumption to GDP; YE means the influence of international trade on GDP, which is the ratio of GDP to exports of goods and services; EP means the per capita exports of goods and service trade, which is the ratio of exports of goods and services trade to the population; $P H$ means the population intensity of productive land, which is the ratio of the population to productive land; and $\varepsilon$ means the reciprocal of the conversion coefficient $\beta$, as shown in Table 2.

Table 2. Definition of variables.

\begin{tabular}{|c|c|c|c|}
\hline $\begin{array}{c}\text { Variable } \\
\text { Parameters }\end{array}$ & Variable Name & Variable Meaning & Unit \\
\hline$E P_{c f e c}$ & $\begin{array}{l}\text { Ecological pressure of the } \\
\text { carbon footprint }\end{array}$ & $\begin{array}{l}\text { Ecological pressure of the carbon footprint in } \\
\text { energy consumption }\end{array}$ & \\
\hline C & $\begin{array}{l}\text { Carbon emission of } \\
\text { non-renewable energy }\end{array}$ & $\begin{array}{l}\text { Carbon emissions arising from } \\
\text { non-renewable energy }\end{array}$ & $\mathrm{t}$ \\
\hline$Q$ & Consumption of non-renewable energy & Consumption of non-renewable energy & tec \\
\hline E & Total energy consumption & $\begin{array}{l}\text { Total energy consumption includes renewable } \\
\text { energy and non-renewable energy }\end{array}$ & tec \\
\hline Y & GDP & Gross domestic product & dollar \\
\hline EXP & Exports of goods and services & Exports of goods and services & dollar \\
\hline POP & Total population & Total population & Person \\
\hline$H$ & Productive land area & Productive land area & $\mathrm{hm}^{2}$ \\
\hline$E F$ & Carbon emission intensity & The $i$ th energy carbon e dollar mission factor & $\mathrm{t} / \mathrm{tec}$ \\
\hline$E S$ & Energy structure & $\begin{array}{l}\text { The proportion of non-renewable energy in the } \\
\text { total energy consumption }\end{array}$ & $\%$ \\
\hline$E I$ & Energy intensity & Ratio of total energy consumption to GDP & tec $/ 10^{3}$ dollar \\
\hline$Y E$ & Influence of international trade on GDP & The ratio of GDP to exports of goods and services & $\%$ \\
\hline$E P$ & $\begin{array}{l}\text { Per capita exports of goods and } \\
\text { service trade }\end{array}$ & $\begin{array}{l}\text { The ratio of exports of goods and services trade } \\
\text { to population }\end{array}$ & $10^{3}$ dollar/Person \\
\hline $\mathrm{PH}$ & Population intensity of productive land & Ratio of population to productive land & person $/ \mathrm{hm}^{2}$ \\
\hline$\varepsilon$ & Coefficient & $\begin{array}{l}\text { The reciprocal of the conversion coefficient } \beta \\
\text { (see Equation (1)) }\end{array}$ & $\mathrm{hm}^{2} / \mathrm{t}$ \\
\hline
\end{tabular}

The contribution of each individual factor to the ecological pressure was calculated by using the LMDI model in Equation (4), and the rate of change of each individual factor was calculated by the decomposition in Equation (5).

$$
\Delta E P_{c f e c}=\Delta E P_{E F}+\Delta E P_{E S}+\Delta E P_{E I}+\Delta E P_{Y E}+\Delta E P_{E P}+\Delta E P_{P H}+\Delta E P_{\varepsilon}
$$


where:

$$
\begin{array}{ll}
\Delta E P_{E S}=W^{T} \times \ln \frac{E S^{T}}{E S^{0}} & \Delta E P_{E I}=W^{T} \times \ln \frac{E I^{T}}{E I^{0}} \\
\Delta E P_{Y E}=W^{T} \times \ln \frac{Y E^{T}}{Y E^{0}} & \Delta E P_{E P}=W^{T} \times \ln \frac{E P^{T}}{E^{0}} \\
\Delta E P_{P H}=W^{T} \times \ln \frac{P H^{T}}{P H^{0}} & W^{T}=\frac{E P_{c f e c}^{T}-E P_{c f e c}^{0}}{\ln \left(E P_{c f e c}^{T} / E P_{c f e c}^{0}\right)}
\end{array}
$$

where:

$$
\begin{gathered}
D=E P_{c f e c}^{T} / E P_{c f e c}^{0}=D_{E F} \times D_{E S} \times D_{E I} \times D_{Y E} \times D_{E P} \times D_{P H} \times D_{\varepsilon} \\
D_{E S}=\frac{E S^{T}}{E S^{0}} D_{E I}=\frac{E I^{T}}{E I^{0}} D_{Y E}=\frac{Y E^{T}}{Y E^{0}} D_{E P}=\frac{E P^{T}}{E P^{0}} D_{P H}=\frac{P H^{T}}{P H^{0}}
\end{gathered}
$$

In Equations (4) and (5), $\Delta E P_{c f e c}$ is the change in $E P_{c f e c} ; \Delta E P_{E F}, \Delta E P_{E S}, \Delta E P_{E I}, \Delta E P_{Y E}, \Delta E P_{E P}$, $\triangle E P_{P H}$, and $\triangle E P_{\varepsilon}$ denote the change in carbon intensity, energy structure, energy intensity, influence of international trade on GDP, per capita exports of goods and service trade, population intensity of productive land, and the conversion coefficient from the 0 th to the $T$ th year, respectively-these are the contribution values; $W^{T}$ is the weight of influence; $D$ represents the change in $E P_{c f e c}, D_{E F}$, $D_{E S}, D_{E I}, D_{Y E}, D_{E P}, D_{P H}$, and $D_{\varepsilon}$ are the rates of change in carbon intensity, energy structure, energy intensity, Influence of international trade on GDP, per capita import and export goods and service trade, population intensity of productive land, and the conversion factor from the 0 th to the $T$ th year, respectively. $E S^{0}, E I^{0}, Y E^{0}, E P^{0}, P H^{0}$ and $E S^{T}, E I^{T}, Y E^{T}, E P^{T}, P H^{T}$ denote the energy structure, energy intensity, influence of international trade on GDP, per capita export goods and service trade volume, and population intensity of productive land in the 0 th year and $T$ th year, respectively.

\section{Data Sources}

According to the bilateral trade agreement of the One Belt and One Road Initiative, combined with the availability of data, 56 countries along the route were selected, as shown in Table 3. Due to the unavailability of data eight countries were excluded: Armenia, Bosnia and Herzegovina, Hungary, Moldova, Montenegro, Nepal, Serbia, and East Timor. The time period used was 1994-2014.

Table 3. The 56 countries along the One Belt and One Road.

\begin{tabular}{cc}
\hline Region & Country Code \\
\hline Mongolia and Russia & RUS, MNG \\
Central Asia & KAZ, KGZ, , TK, TKM, UZB \\
West Asia and North Africa & QAT, ARE, KWT, ISR, BHR, SAU, OMN, TUR, LBN, AZE, IRQ, IRN, JOR, GEO, EGY, YEM, SYR \\
Central and Eastern & SVN, EST, CZE, SVK, LTU, LVA, POL, HRV, ROM, BLR, BGR, MKD, ALB, UKR \\
Southeast Asia & SGP, BRN, MYS, THA, IDN, PHL, VNM, LAO, MMR, KHM \\
South Asia & MDV, LKA, BTN, IND, PAK, BGD, AFG \\
Eastern Asia & CHN \\
\hline
\end{tabular}

The information analysis center of the Oak Ridge National Laboratory in the United States Carbon Dioxide Information Analysis Center (CDIAC) provides carbon emission data [71]. The primary energy sources for the countries studied mainly comprise coal, oil, and natural gas. Compiling data on energy consumption and carbon emissions shows that the carbon emissions of countries along the One Belt and One Road are on the rise. The highest value of the carbon emissions in 2012 was $486.41 \times 10^{7} \mathrm{t}$ after which a downward trend occurred, showing that various countries began to focus on green and low-carbon development models. Carbon emissions from the energy consumption of coal, oil, and natural gas are also decreasing. From 2000-2012, the carbon emissions from oil and natural gas production have changed by a small amount, and remained within the range $50 \times 10^{7}-70 \times 10^{7} \mathrm{t}$. Of these, coal combustion is the main source of carbon emissions and is growing rapidly. In 2012, the carbon consumption of coal consumption reached $251.9 \times 10^{7} \mathrm{t}$, which was 1.5 times that of oil and natural gas consumption. The trends are shown in Figure 2. 


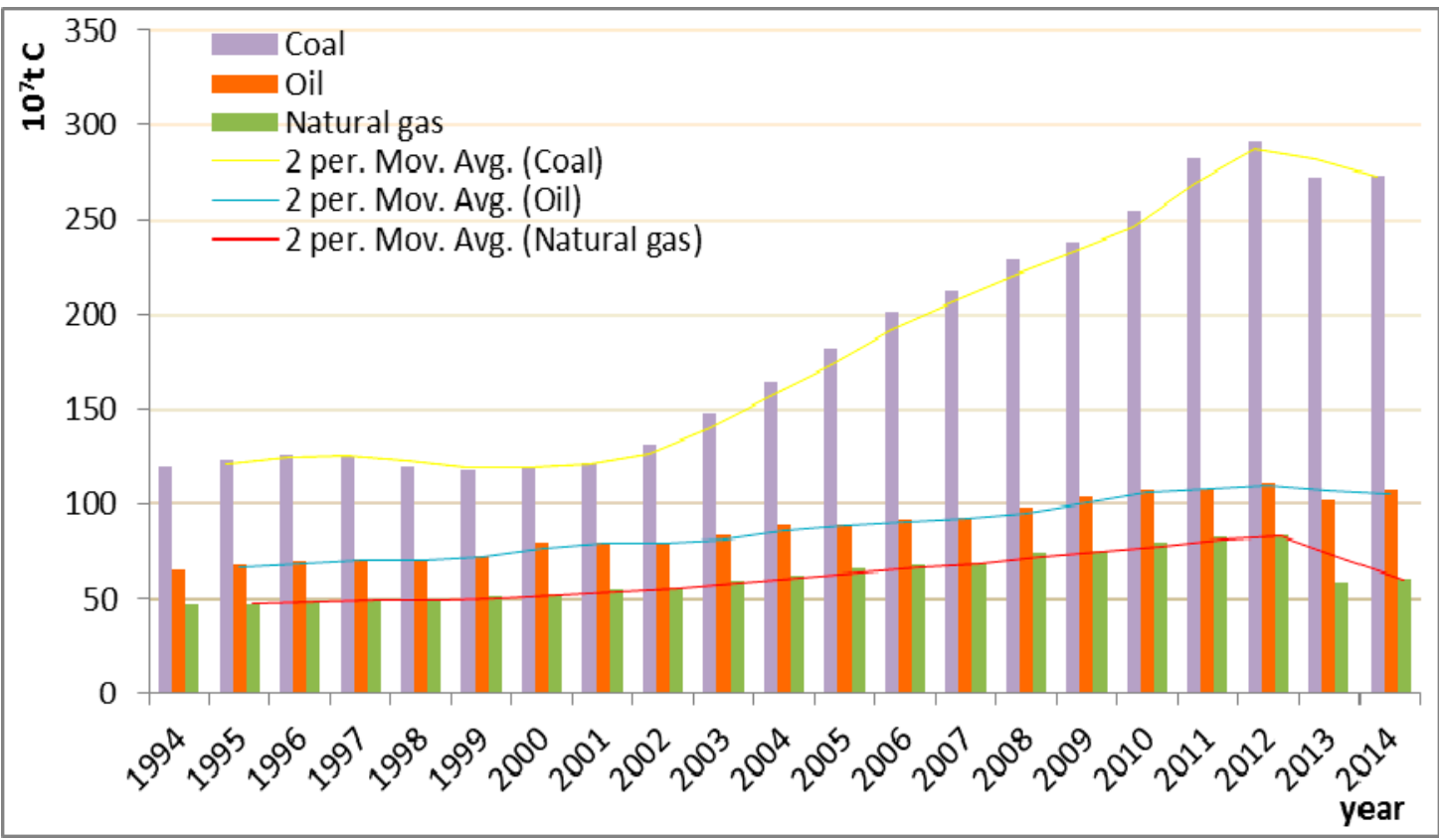

Figure 2. The changes of carbon emissions of different energy consumption modes from 1994-2014.

Data about the productive land area, population, and GDP was taken from the World Bank public data resource [72]. Taking into account the integrity and continuity of the data, a small amount of data was processed using interpolation. In order to analyze regional differences, 56 countries along the route were divided into seven regions: Mongolia, Russia, Central Asia, West Asia, North Africa, Central and Eastern Europe, Southeast Asia, South Asia, and East Asia (Table 3). The spatial layout is shown in Figure 3.



Figure 3. The regional distribution of 56 countries.

\section{Results and Analysis}

\subsection{The Carbon Footprint in Energy Consumption}

The changes of the carbon footprint in energy consumption (CFEC) derived from Equation (1) for 56 countries, from 1994-2014, are shown in Figure 4. 


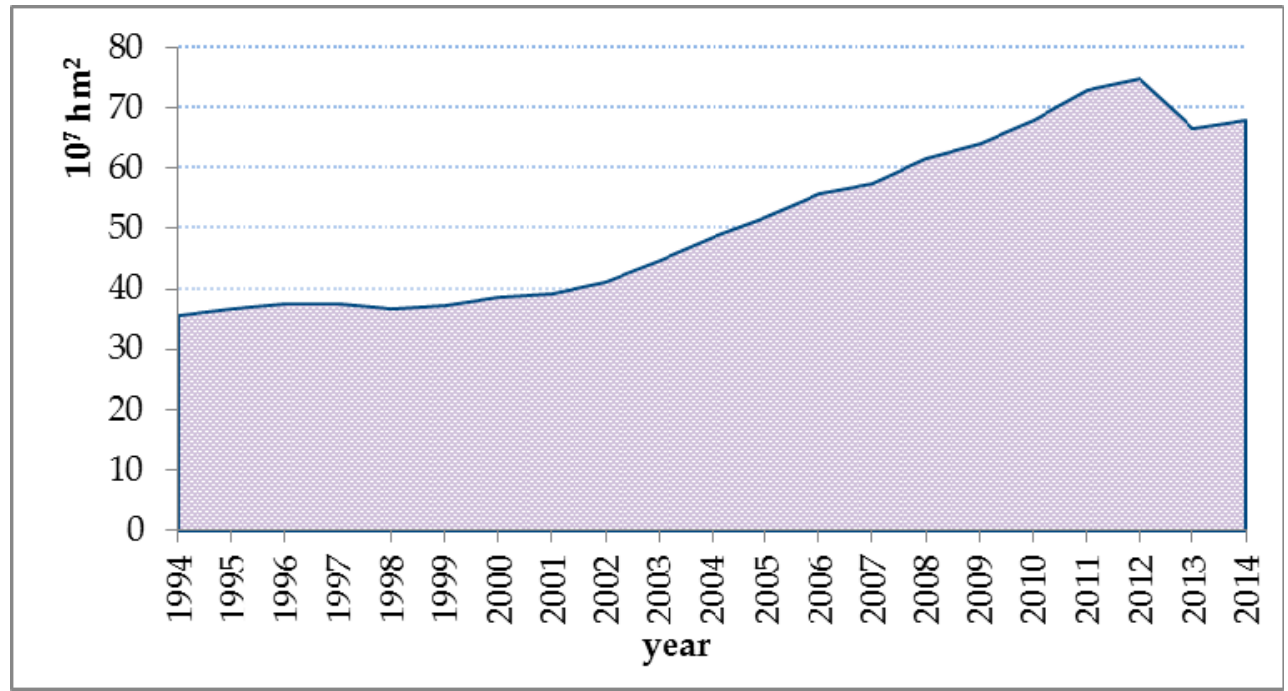

Figure 4. The changes in the sum of CFEC of 56 countries from 1994-2014.

Figure 4 indicates that the carbon footprint of countries along the One Belt and One Road line show a single-peak evolution over time. The value from 1994-2000 remained basically unchanged. With the increase of energy consumption, the carbon footprint increased during the period 2001-2012. In 2012, the peak value of $74.9 \times 10^{7} \mathrm{hm}^{2}$ was reached, after which there was a downward trend. This is the same trend as for carbon emissions of countries along the One Belt and One Road during the same period.

\subsection{Ecological Pressure of the Carbon Footprint in Energy Consumption}

The $E P_{c f e c}$ values of 56 countries from 1994-2014 were calculated according to Equation (2), and are shown in Tables 4 and 5.

Table 4. Change values of $E P_{c f e c}$ in 1994-2014 in light pressure states.

\begin{tabular}{cccccccccccc}
\hline Country & $\mathbf{1 9 9 4}$ & $\mathbf{1 9 9 6}$ & $\mathbf{1 9 9 8}$ & $\mathbf{2 0 0 0}$ & $\mathbf{2 0 0 2}$ & $\mathbf{2 0 0 4}$ & $\mathbf{2 0 0 6}$ & $\mathbf{2 0 0 8}$ & $\mathbf{2 0 1 0}$ & $\mathbf{2 0 1 2}$ & $\mathbf{2 0 1 4}$ \\
\hline AFG & 0.00 & 0.00 & 0.00 & 0.00 & 0.00 & 0.00 & 0.00 & 0.00 & 0.01 & 0.01 & 0.01 \\
ALB & 0.01 & 0.01 & 0.00 & 0.00 & 0.00 & 0.01 & 0.00 & 0.00 & 0.02 & 0.02 & 0.03 \\
AZE & 0.29 & 0.29 & 0.26 & 0.25 & 0.28 & 0.30 & 0.28 & 0.24 & 0.28 & 0.29 & 0.00 \\
BGD & 0.08 & 0.11 & 0.10 & 0.12 & 0.14 & 0.16 & 0.19 & 0.20 & 0.24 & 0.28 & 0.30 \\
BGR & 0.36 & 0.38 & 0.36 & 0.32 & 0.34 & 0.36 & 0.38 & 0.40 & 0.36 & 0.36 & 0.35 \\
BLR & 0.29 & 0.27 & 0.26 & 0.24 & 0.24 & 0.26 & 0.28 & 0.28 & 0.28 & 0.29 & 0.29 \\
BTN & 0.01 & 0.02 & 0.02 & 0.02 & 0.03 & 0.02 & 0.02 & 0.03 & 0.03 & 0.04 & 0.05 \\
CHN & 0.23 & 0.26 & 0.24 & 0.25 & 0.28 & 0.39 & 0.48 & 0.56 & 0.64 & 0.73 & 0.74 \\
CZE & 1.20 & 1.20 & 1.17 & 1.19 & 1.15 & 1.12 & 1.18 & 1.12 & 1.08 & 0.98 & 0.94 \\
EST & 0.70 & 0.74 & 0.64 & 0.61 & 0.85 & 0.90 & 0.72 & 0.77 & 0.78 & 0.75 & 0.81 \\
GEO & 0.08 & 0.06 & 0.07 & 0.06 & 0.04 & 0.07 & 0.10 & 0.08 & 0.10 & 0.13 & 0.13 \\
HRV & 0.28 & 0.34 & 0.39 & 0.63 & 0.69 & 0.72 & 0.70 & 0.67 & 0.59 & 0.53 & 0.43 \\
IDN & 0.20 & 0.22 & 0.18 & 0.21 & 0.24 & 0.24 & 0.26 & 0.30 & 0.30 & 0.44 & 0.30 \\
IND & 0.17 & 0.20 & 0.21 & 0.23 & 0.23 & 0.25 & 0.28 & 0.34 & 0.37 & 0.44 & 0.49 \\
IRN & 0.14 & 0.16 & 0.15 & 0.23 & 0.24 & 0.24 & 0.38 & 0.42 & 0.45 & 0.47 & 0.50 \\
IRQ & 0.32 & 0.32 & 0.33 & 0.34 & 0.39 & 0.47 & 0.39 & 0.40 & 0.48 & 0.61 & 0.62 \\
JOR & 0.46 & 0.50 & 0.52 & 0.56 & 0.62 & 0.70 & 0.79 & 0.83 & 0.81 & 0.90 & 0.96 \\
\hline
\end{tabular}


Table 4. Cont.

\begin{tabular}{|c|c|c|c|c|c|c|c|c|c|c|c|}
\hline Country & 1994 & 1996 & 1998 & 2000 & 2002 & 2004 & 2006 & 2008 & 2010 & 2012 & 2014 \\
\hline KAZ & 0.03 & 0.02 & 0.02 & 0.03 & 0.03 & 0.04 & 0.05 & 0.05 & 0.05 & 0.05 & 0.00 \\
\hline KGZ & 0.02 & 0.02 & 0.02 & 0.02 & 0.02 & 0.02 & 0.02 & 0.03 & 0.02 & 0.04 & 0.03 \\
\hline KHM & 0.01 & 0.01 & 0.02 & 0.02 & 0.02 & 0.02 & 0.02 & 0.03 & 0.03 & 0.04 & 0.05 \\
\hline LAO & 0.01 & 0.01 & 0.01 & 0.02 & 0.02 & 0.03 & 0.03 & 0.01 & 0.02 & 0.02 & 0.01 \\
\hline LKA & 0.09 & 0.12 & 0.13 & 0.17 & 0.19 & 0.21 & 0.19 & 0.18 & 0.20 & 0.23 & 0.27 \\
\hline LTU & 0.23 & 0.19 & 0.19 & 0.15 & 0.19 & 0.21 & 0.20 & 0.23 & 0.20 & 0.20 & 0.18 \\
\hline LVA & 0.18 & 0.20 & 0.19 & 0.16 & 0.18 & 0.18 & 0.18 & 0.18 & 0.18 & 0.15 & 0.14 \\
\hline MKD & 0.33 & 0.37 & 0.40 & 0.40 & 0.33 & 0.36 & 0.36 & 0.35 & 0.31 & 0.28 & 0.24 \\
\hline MMR & 0.02 & 0.03 & 0.03 & 0.04 & 0.03 & 0.04 & 0.04 & 0.03 & 0.04 & 0.03 & 0.07 \\
\hline MNG & 0.00 & 0.00 & 0.00 & 0.00 & 0.00 & 0.00 & 0.00 & 0.00 & 0.01 & 0.01 & 0.01 \\
\hline PAK & 0.09 & 0.10 & 0.11 & 0.11 & 0.12 & 0.14 & 0.16 & 0.17 & 0.17 & 0.17 & 0.17 \\
\hline PHL & 0.19 & 0.21 & 0.23 & 0.25 & 0.24 & 0.25 & 0.22 & 0.25 & 0.27 & 0.27 & 0.32 \\
\hline POL & 0.73 & 0.79 & 0.72 & 0.66 & 0.72 & 0.76 & 0.82 & 0.82 & 0.89 & 0.84 & 0.80 \\
\hline ROM & 0.33 & 0.35 & 0.27 & 0.25 & 0.27 & 0.28 & 0.30 & 0.28 & 0.22 & 0.24 & 0.20 \\
\hline RUS & 0.30 & 0.28 & 0.28 & 0.28 & 0.29 & 0.30 & 0.31 & 0.30 & 0.33 & 0.31 & 0.00 \\
\hline SAU & 0.07 & 0.06 & 0.05 & 0.07 & 0.08 & 0.09 & 0.10 & 0.10 & 0.12 & 0.13 & 0.14 \\
\hline SVK & 0.67 & 0.68 & 0.65 & 0.59 & 0.70 & 0.80 & 0.80 & 0.76 & 0.74 & 0.68 & 0.63 \\
\hline SVN & 0.97 & 1.13 & 1.22 & 1.09 & 1.20 & 1.26 & 1.30 & 1.11 & 0.99 & 0.96 & 0.81 \\
\hline SYR & 0.11 & 0.12 & 0.14 & 0.14 & 0.11 & 0.14 & 0.15 & 0.19 & 0.17 & 0.12 & 0.08 \\
\hline THA & 0.25 & 0.32 & 0.32 & 0.35 & 0.41 & 0.48 & 0.49 & 0.49 & 0.53 & 0.54 & 0.56 \\
\hline TJK & 0.02 & 0.03 & 0.02 & 0.02 & 0.02 & 0.02 & 0.02 & 0.02 & 0.02 & 0.02 & 0.04 \\
\hline TKM & 0.04 & 0.04 & 0.04 & 0.04 & 0.05 & 0.06 & 0.06 & 0.07 & 0.07 & 0.08 & 0.08 \\
\hline TUR & 0.15 & 0.18 & 0.19 & 0.21 & 0.19 & 0.21 & 0.25 & 0.28 & 0.29 & 0.32 & 0.34 \\
\hline UKR & 0.44 & 0.41 & 0.33 & 0.32 & 0.32 & 0.34 & 0.32 & 0.31 & 0.30 & 0.30 & 0.23 \\
\hline UZB & 0.16 & 0.16 & 0.18 & 0.18 & 0.20 & 0.19 & 0.18 & 0.19 & 0.16 & 0.18 & 0.16 \\
\hline VNM & 0.14 & 0.17 & 0.22 & 0.22 & 0.26 & 0.33 & 0.36 & 0.40 & 0.44 & 0.44 & 0.52 \\
\hline YEM & 0.02 & 0.02 & 0.02 & 0.02 & 0.03 & 0.03 & 0.04 & 0.04 & 0.04 & 0.03 & 0.04 \\
\hline
\end{tabular}

Table 5. Change values of $E P_{c f e c}$ in 1994-2014 in high pressure states.

\begin{tabular}{cccccccccccc}
\hline Country & $\mathbf{1 9 9 4}$ & $\mathbf{1 9 9 6}$ & $\mathbf{1 9 9 8}$ & $\mathbf{2 0 0 0}$ & $\mathbf{2 0 0 2}$ & $\mathbf{2 0 0 4}$ & $\mathbf{2 0 0 6}$ & $\mathbf{2 0 0 8}$ & $\mathbf{2 0 1 0}$ & $\mathbf{2 0 1 2}$ & $\mathbf{2 0 1 4}$ \\
\hline MYS & 0.48 & 0.66 & 0.59 & 0.66 & 0.70 & 0.87 & 0.84 & 1.03 & 1.04 & 1.06 & 1.18 \\
LBN & 0.76 & 0.82 & 1.00 & 0.98 & 0.99 & 0.96 & 0.79 & 0.96 & 1.14 & 1.27 & 1.36 \\
OMN & 0.54 & 0.54 & 0.56 & 0.70 & 0.71 & 0.65 & 1.00 & 1.09 & 1.22 & 1.54 & 1.59 \\
EGY & 1.00 & 1.23 & 1.44 & 1.65 & 1.39 & 1.65 & 1.91 & 2.12 & 2.07 & 2.15 & 1.99 \\
ISR & 3.33 & 3.74 & 4.02 & 4.25 & 4.28 & 4.63 & 4.93 & 5.35 & 5.51 & 5.78 & 4.78 \\
MDV & 1.04 & 1.52 & 1.58 & 2.10 & 2.08 & 2.55 & 3.98 & 4.42 & 4.97 & 5.90 & 7.09 \\
BRN & 11.11 & 12.04 & 13.43 & 11.69 & 10.05 & 11.99 & 12.49 & 23.59 & 18.87 & 22.45 & 19.55 \\
ARE & 7.84 & 3.97 & 7.77 & 8.10 & 5.88 & 8.00 & 8.88 & 11.09 & 15.73 & 18.20 & 21.95 \\
KWT & 11.08 & 14.16 & 14.72 & 14.76 & 15.85 & 17.29 & 20.21 & 22.54 & 24.37 & 27.83 & 25.71 \\
QAT & 19.38 & 20.34 & 20.32 & 21.73 & 25.84 & 27.11 & 35.10 & 34.53 & 44.04 & 57.73 & 66.29 \\
BHR & 68.49 & 72.48 & 85.36 & 84.91 & 71.52 & 83.57 & 91.52 & 151.32 & 140.00 & 126.95 & 149.36 \\
SGP & 1853.18 & 1480.71 & 1462.29 & 1492.58 & 1452.46 & 1241.78 & 1416.69 & 1758.35 & 2587.78 & 1710.52 & 2876.59 \\
\hline
\end{tabular}

In general, the $E P_{c f e c}$ has increased in all countries. Of these, 44 countries are under light pressure and 12 countries are under high pressure. Some countries are already under excessive high pressure (i.e., the $E P_{c f e c}$ of SGP reached 2876.59, which is 50.49 times the average value of 56.97 in 2014). Carbon emissions from energy consumption in some countries, such as Singapore, Bahrain, Qatar, Kuwait, UAE, Israel, and Brunei, have far exceeded the digestion capacity of the productive land. On the one hand, these countries are more dependent on non-renewable energy, and on the other hand, the area of productive land is relatively small. Countries with light pressure can also naturally digest carbon emissions from energy consumption, especially countries with an $E P_{c f e c}$ of less than 0.1 , such as Kazakhstan, Mongolia, and Saudi Arabia. This is directly related to the large area of productive land in these countries. Therefore, protecting or expanding productive land area has a direct impact on reduction of the $E P_{c f e c}$. 
Figure 5 shows the spatial evolution of the $E P_{c f e c}$ in 56 countries in 1994, 2002, 2008, and 2014. It can be seen that there is a significant difference in the $E P_{c f f c}$ among these countries. Mongolia, Kazakhstan, Kyrgyzstan, Tajikistan, Afghanistan, Laos, Cambodia, Myanmar, Yemen, and other countries were under light pressure. The $E P_{c f e c}$ is always below 0.05 and the change is small. Although China, Iraq, Jordan, and Thailand, among others, are under light pressure, but with a rapid rate of increase- the $E P_{c f e c}$ in these countries has increased from a relatively low level to over 0.5 , which is related to the increase in carbon emissions in these countries. Oman, Lebanon, and Malaysia have changed from light pressure to heavy pressure, which is related to the small changes in productive land in these countries and the growth of carbon emissions. In the Czech Republic, Croatia, Slovenia, Russia, and some other countries, the $E P_{c f e c}$ has shown a downward trend, and some countries have shifted from a heavy state of pressure to a light pressure state. This is related to the decline in carbon emissions in these countries, mainly because the carbon emissions from coal are decreasing.

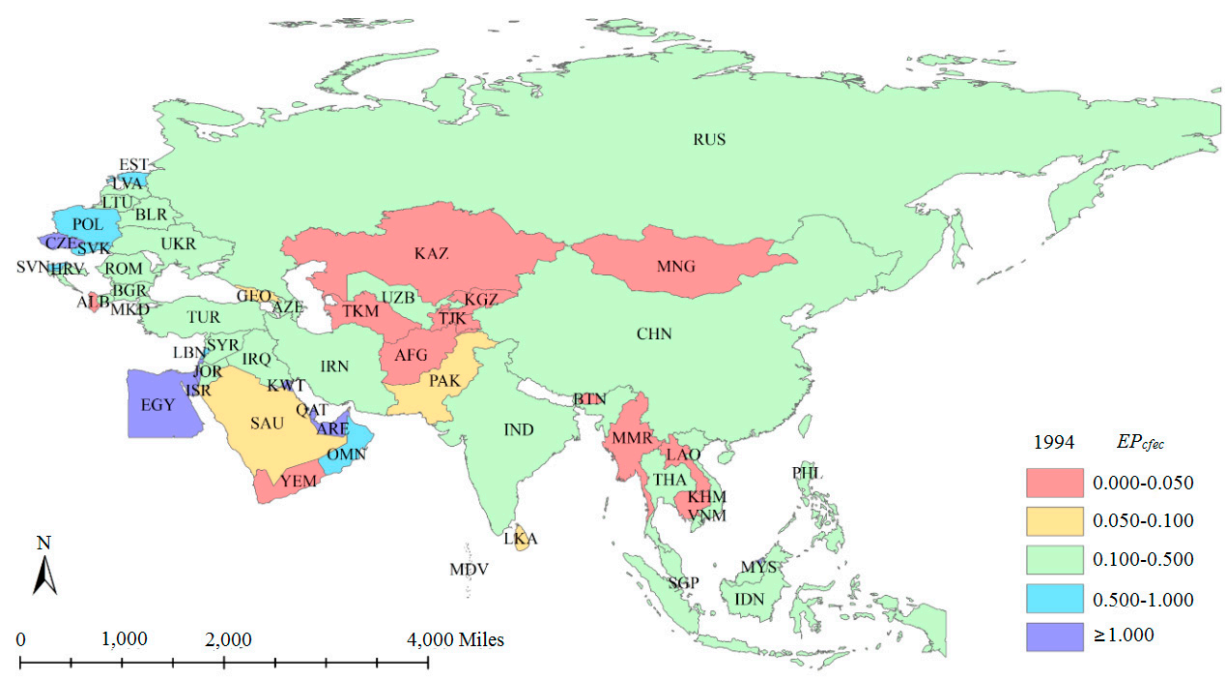

(a) 1994

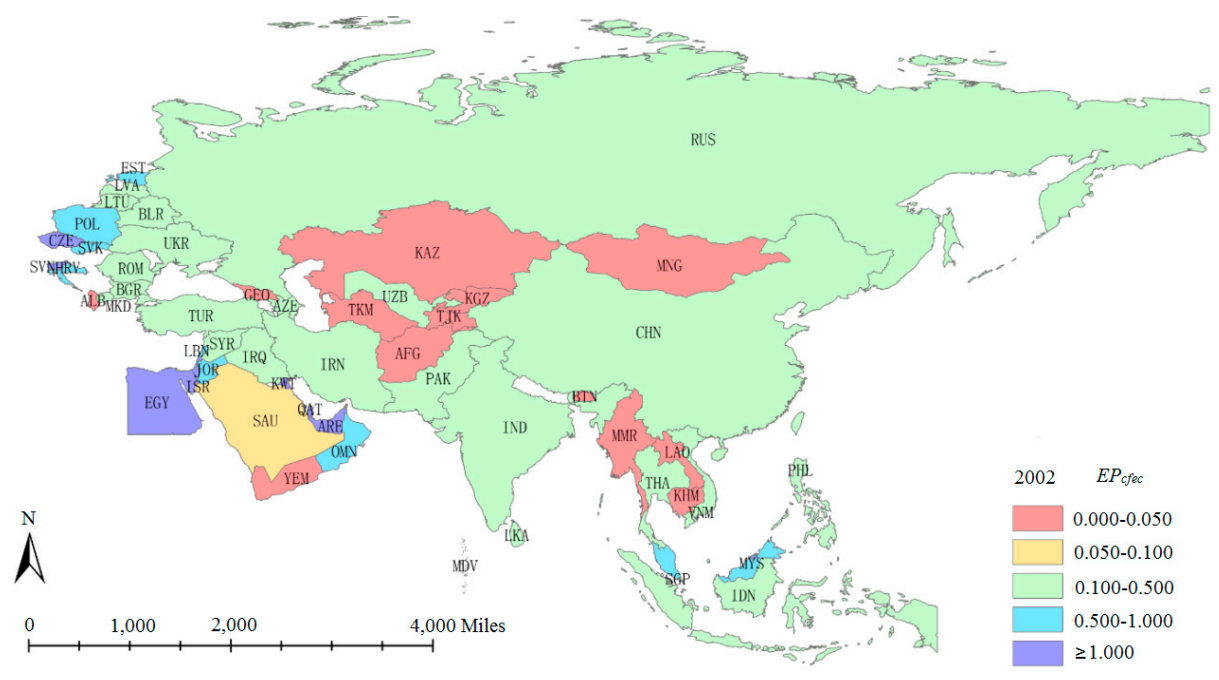

(b) 2002

Figure 5. Cont. 


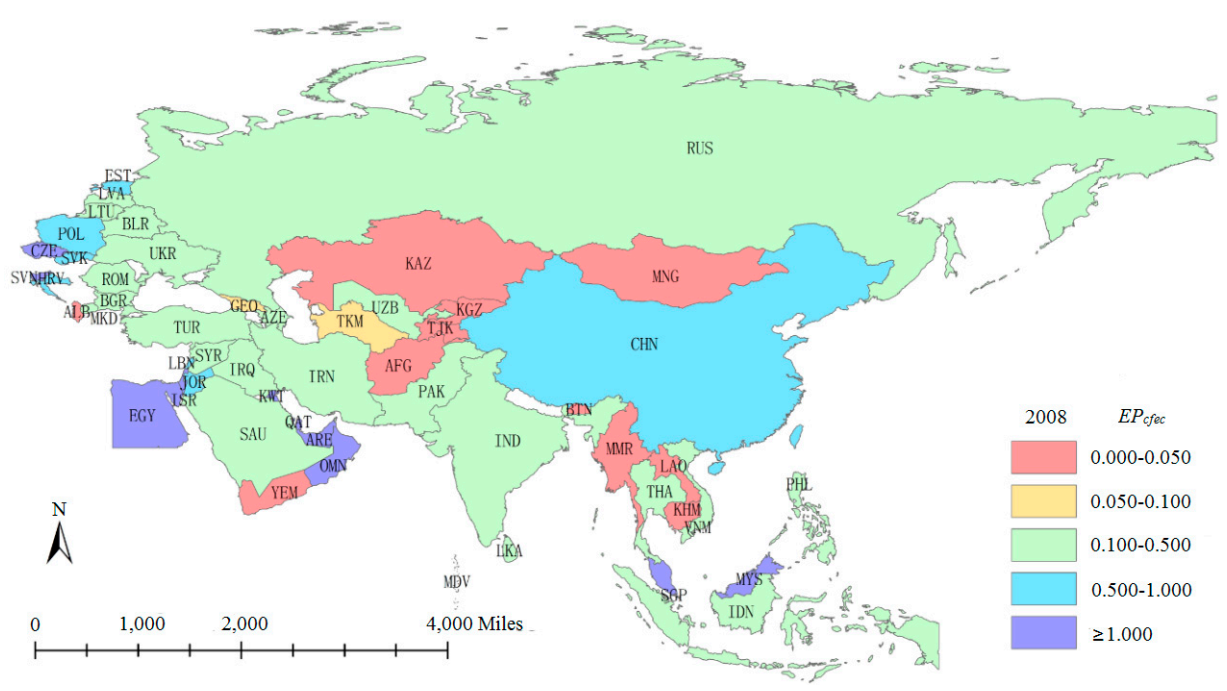

(c) 2008

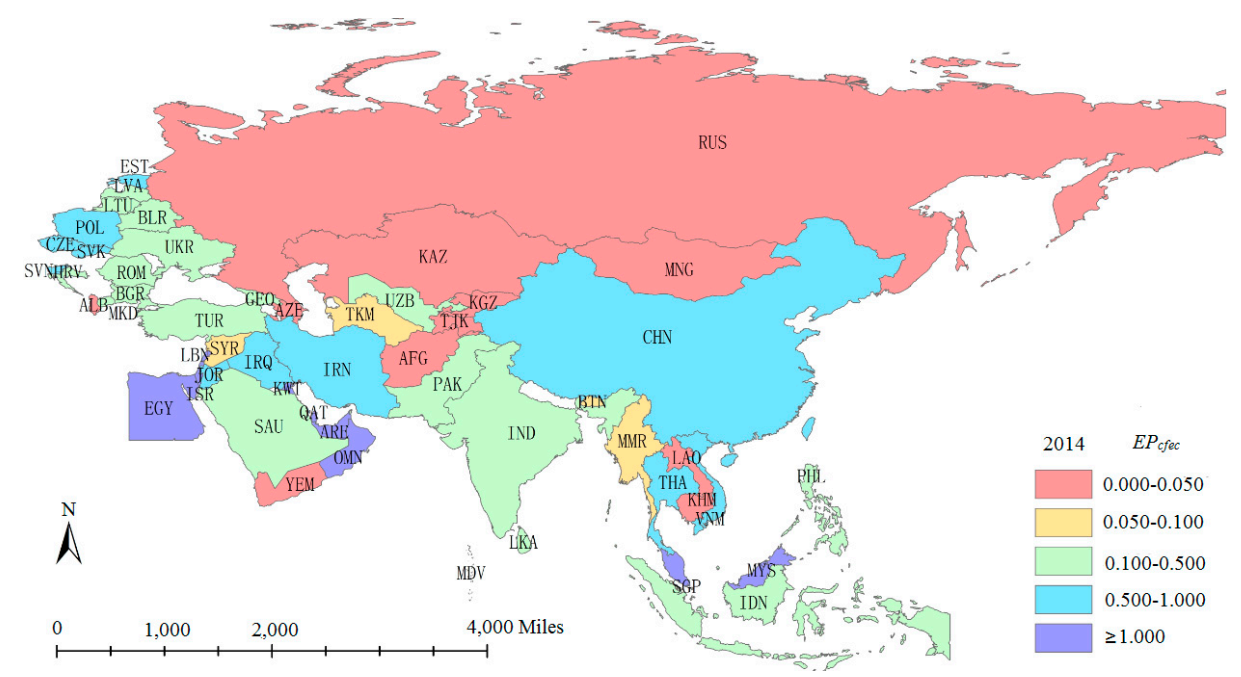

(d) 2014

Figure 5. Spatial changes of the $E P_{c f e c}$ in (a) 1994; (b) 2002; (c) 2008; and (d) 2014.

Figure 6 shows the time variation of the $E P_{c f e c}$ in seven regions. The areas with greater ecological stress are mainly located in Southeast Asia, West Asia, and North Africa, and the lowest $E P_{c f e c}$ value is 6.71. However, in Central Asia, where the level of income is relatively low, and in Mongolia and Russia, where the area of productive land is relatively large, the ecological pressure is relatively low, and the $E P_{c f e c}$ value is between 0.05 and 0.17 . 


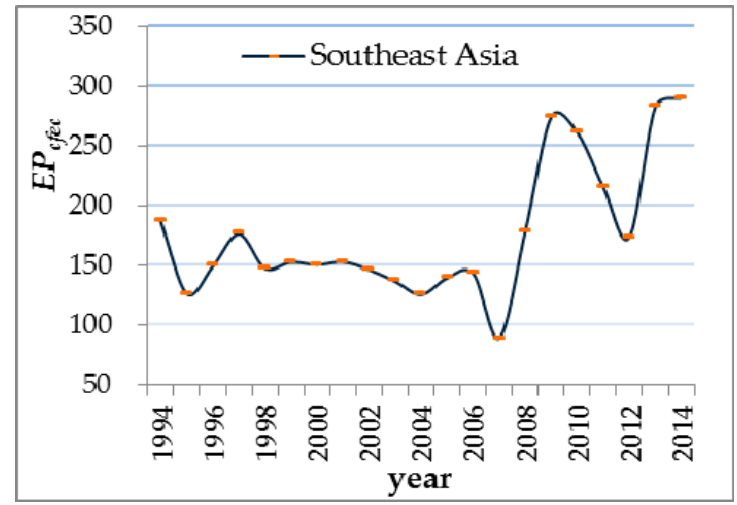

(a)

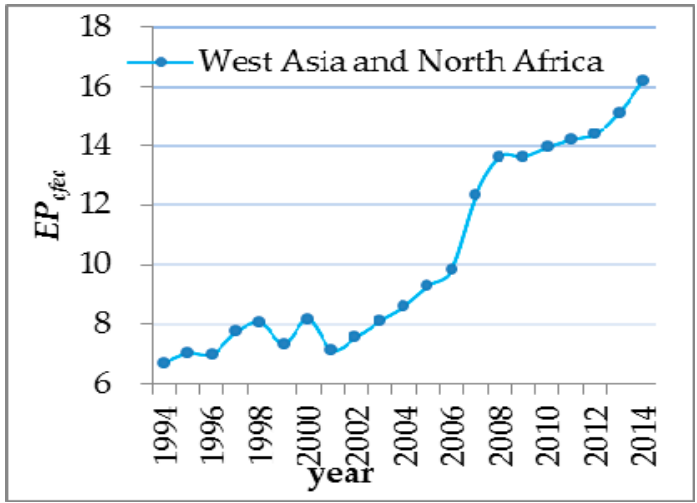

(b)

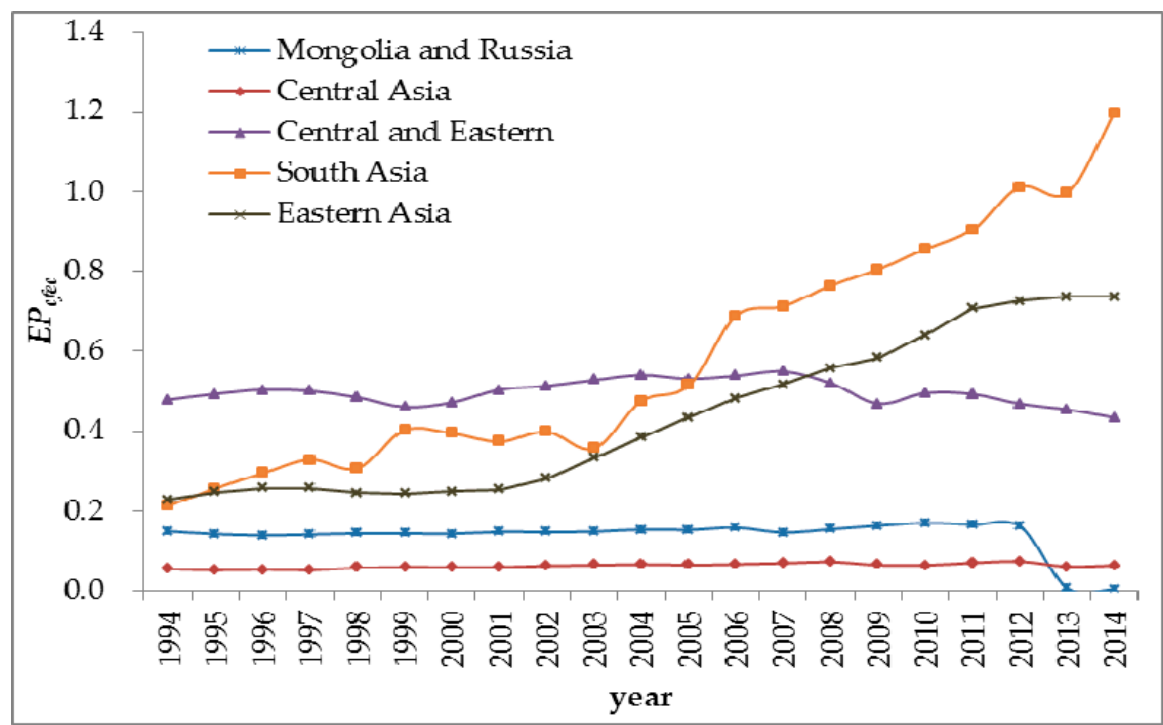

(c)

Figure 6. The $E P_{c f e c}$ of the seven regions from 1994-2014.

\subsection{Driving Factor Decomposition of $E P_{c f e c}$}

\subsubsection{Factors Decomposition for the Overall Region}

Equations (3)-(5) were used to decompose the ecological pressure of the carbon footprint in energy consumption, and calculate the contribution and rate of change of $E P_{c f e c}$ for different factors. Figure 7 shows changes in the contribution value of each factor to $E P_{c f e c}$, and Figure 8 shows the rate of change of each factor. A contribution value greater than 0 indicates that the factor has a promoting effect on the $E P_{c f e c}$, and a value of less than 0 shows an inhibitory effect. The greater the absolute value, the greater the influence. 


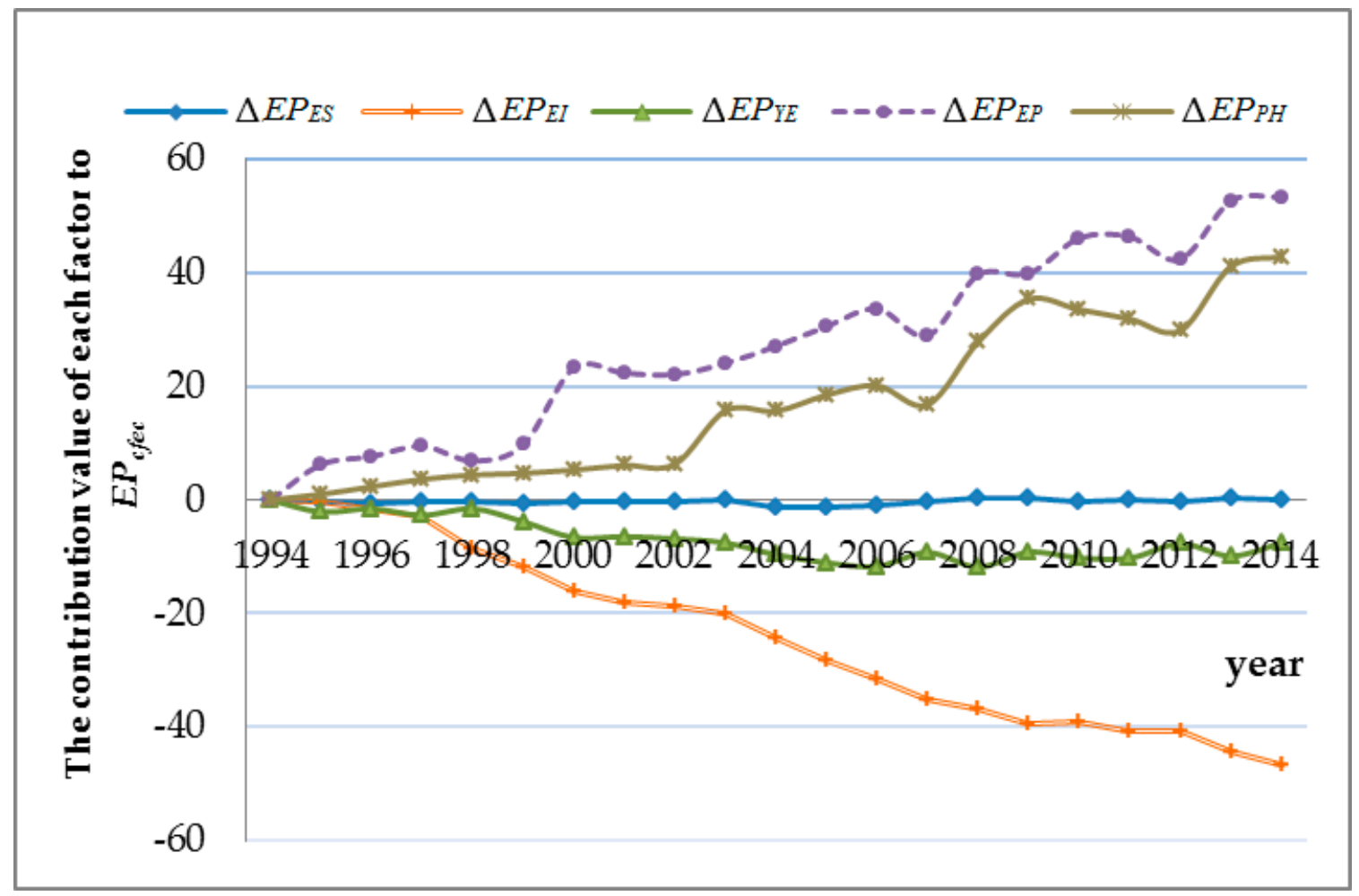

Figure 7. The contribution of $E S, E I, Y E, E P$, and $P H$ to the $E P_{c f e c}$.

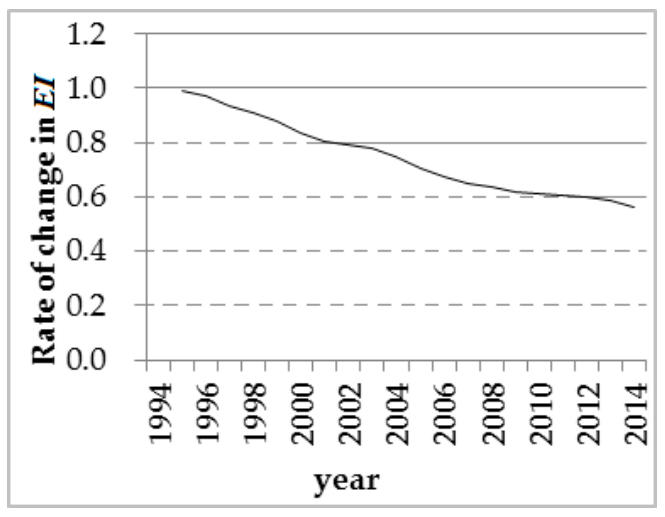

(a)

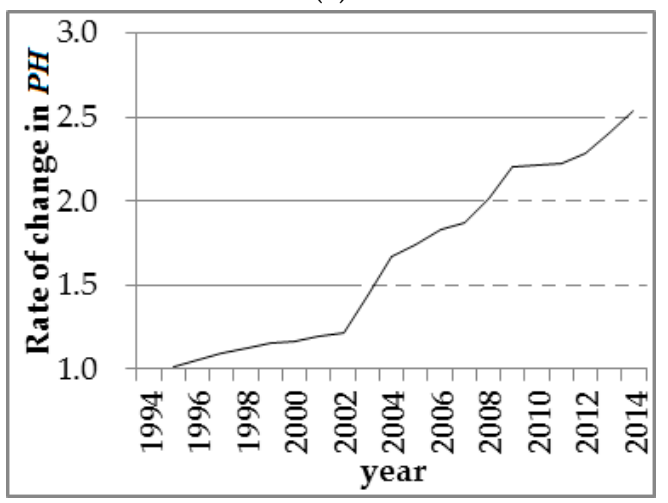

(c)

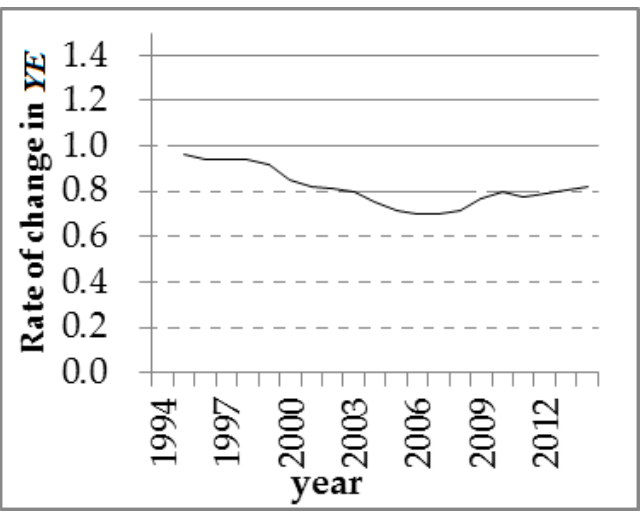

(b)

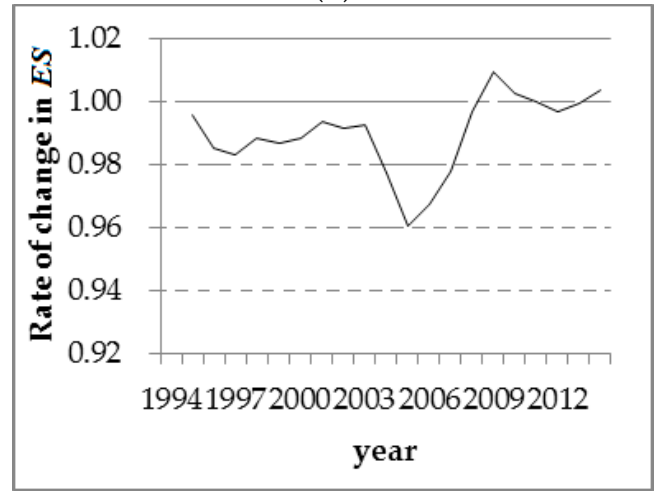

(d)

Figure 8. Cont. 




(e)

Figure 8. The rate of change in $E S, E I, Y E, E P, P H$ to $E P_{c f e c}$.

Note that in the original statistics for Myanmar, the maximum value of the influence of international trade on GDP is 1005.36 and the minimum is 4.98 , which is abnormal. Including the factor analysis of the factors in the overall region, the contribution of other factors to the $E P_{c f e c}$ was diluted. Therefore, Myanmar was excluded from this part of the analysis.

As can be seen from Figure 7, the five factors that contributed to $E P_{c f e c}$ in 2014 are ranked as follows: energy intensity, influence of international trade on GDP, energy structure, population intensity of productive land, and per capita exports of goods and service trade. Among them, three factors (energy intensity, influence of international trade on GDP, and energy structure) play a decisive role; two factors (population intensity of productive land, per capita export goods and service trade) play a catalytic role.

(1) Energy intensity (EI): From 1994-2014, EI had an inhibitory effect on the $E P_{c f e c}$ gradually increased over time. The contribution in 2014 was -46.64 , and the rate of change was 0.55 , as shown in Figure 8a. The energy consumption intensity of the countries also decreased significantly over the same period. Countries should continue to implement energy-saving and emission-reduction measures, significantly reduce energy consumption per unit, in order to strengthen the inhibitory effect of energy consumption intensity on the $E P_{c f e c}$.

(2) Influence of international trade on GDP (YE): in 1994-2014, the contribution of this factor was between -12 and 0 , and the rate of change was between 0.69 and 1, as shown in Figure $8 \mathrm{~b}$. This factor has an inhibitory effect on the $E P_{c f f c}$ but shows a slight weakening trend. In the same period, YE gradually decreased and export dependency rose slowly. This shows that international trade has gradually enhanced the economic growth of countries along the One Belt and One Road and has also increased the ecological pressure arising from the carbon footprint. Therefore, countries along the One Belt and One Road urgently need to develop their foreign trade in accordance with low-carbon, environmental protection, and green models.

(3) Energy structure (ES): from 1994-2014, the contribution of the ES to the $E P_{c f f e c}$ was between -1.3 and 0.36 , and the rate of change was between 0.96 and 1.01, as shown in Figure 8c. The impact on the $E P_{c f e c}$ fluctuated, but not by much. In general, it showed inhibitory effects and only acted as a promoter in 2008 and 2011 during which time its promotion was small. The ES mainly depends on the proportion of non-renewable energy, such as coal, oil, and natural gas. This proportion has been relatively large in the countries along the One Belt and One Road, and has remained at about 78\%. Therefore, there is a very great potential for reducing the ecological pressure of the carbon footprint in energy consumption by adjusting the energy structure.

(4) Population intensity of productive land $(\mathrm{PH})$ : This factor has a significant role in increasing the $E P_{c f e c}$ and is rising year by year. In 2014, the contribution was 42.86 and the rate of change was 2.57 , as shown in Figure $8 \mathrm{~d}$. In the same period, the $P H$ increased continuously, and the population 
intensity in 2014 was 2.57 times that of 1994. Countries along the One Belt and One Road are mostly developing countries and underdeveloped countries, with a large population base and strong growth inertia. It is hard to reduce the population size in the short term. Therefore, the key to reduce the $E P_{c f e c}$ is to protect or expand the area of productive land, such as forests and grasslands.

(5) Per capita exports of goods and services $(E P)$ : This factor made the largest contribution to the $E P_{c f f c}$. From 1999-2014, the contribution to the $E P_{c f e c}$ rose dramatically from 9.72-53.39, an increase of 5.49 times, and the rate of change climbed from 1.35 to 3.24, an increase of 2.4 times, as shown in Figure 8e. In the same period, the EP also experienced rapid growth, which promoted the economic growth of all countries. This shows that the export trade of goods and services in certain countries is in a period of high growth, accompanied by high energy consumption. This is consistent with the $Y E$ factor. Therefore, the development of low-carbon and green international trade will be the key to reducing the $E P_{c f e c}$. While actively conducting foreign trade, countries along the One Belt and One Road need to provide new impetus for foreign trade development through means such as technological innovation and structural adjustment.

\subsubsection{Decomposition Analysis of Factors in Different Sub-Regions}

Changes of the studied ecological pressure drivers across the seven sub-regions are summarized in Table 6.

Table 6. Factor decomposition of the $E P_{c f e c}$ for the seven regions studied from 1994-2014.

\begin{tabular}{|c|c|c|c|c|c|c|c|c|c|c|c|}
\hline Period & Region & $\Delta E P_{E S}$ & $D_{E S}$ & $\Delta E P_{E I}$ & $D_{E I}$ & $\Delta E P_{Y E}$ & $D_{Y E}$ & $\Delta E P_{E P}$ & $D_{E P}$ & $\Delta E P_{P H}$ & $D_{P H}$ \\
\hline \multirow{7}{*}{ 1994-1999 } & 1 & 0.00 & 0.99 & -0.01 & 0.91 & -0.01 & 0.97 & 0.01 & 1.05 & 0.00 & 1.00 \\
\hline & 2 & 0.00 & 0.99 & 0.00 & 0.95 & -0.01 & 0.89 & -0.01 & 0.87 & 0.00 & 1.03 \\
\hline & 3 & -0.06 & 0.99 & -0.81 & 0.90 & -0.30 & 0.96 & 2.19 & 1.38 & 0.88 & 1.13 \\
\hline & 4 & -0.01 & 0.98 & -0.05 & 0.90 & -0.01 & 0.98 & 0.34 & 2.09 & 0.01 & 1.02 \\
\hline & 5 & -5.67 & 0.97 & 4.47 & 1.03 & -23.13 & 0.88 & 19.01 & 1.12 & 13.81 & 1.09 \\
\hline & 6 & 0.02 & 1.08 & -0.01 & 0.98 & -0.02 & 0.92 & 0.05 & 1.19 & 0.01 & 1.06 \\
\hline & 7 & 0.00 & 1.02 & -0.04 & 0.87 & 0.01 & 1.03 & 0.04 & 1.20 & 0.01 & 1.03 \\
\hline \multirow{7}{*}{ 2000-2004 } & 1 & 0.00 & 0.97 & -0.04 & 0.77 & -0.04 & 0.78 & 0.07 & 1.56 & 0.00 & 0.99 \\
\hline & 2 & 0.00 & 0.96 & -0.01 & 0.81 & -0.02 & 0.70 & 0.02 & 1.40 & 0.01 & 1.11 \\
\hline & 3 & -0.10 & 0.99 & -1.88 & 0.77 & -1.84 & 0.78 & 12.85 & 6.27 & 2.28 & 1.37 \\
\hline & 4 & -0.02 & 0.96 & -0.17 & 0.71 & -0.10 & 0.82 & 0.56 & 3.13 & 0.06 & 1.12 \\
\hline & 5 & -1.07 & 0.99 & -12.37 & 0.93 & -54.74 & 0.72 & 59.16 & 1.45 & 51.80 & 1.40 \\
\hline & 6 & 0.02 & 1.10 & -0.03 & 0.90 & -0.04 & 0.86 & 0.12 & 1.48 & 0.01 & 1.02 \\
\hline & 7 & 0.02 & 1.06 & -0.10 & 0.68 & -0.07 & 0.79 & 0.23 & 2.47 & 0.02 & 1.08 \\
\hline \multirow{7}{*}{ 2005-2009 } & 1 & 0.00 & 0.98 & -0.07 & 0.65 & -0.03 & 0.85 & 0.10 & 1.94 & 0.00 & 0.98 \\
\hline & 2 & 0.00 & 0.99 & -0.03 & 0.64 & -0.01 & 0.88 & 0.04 & 1.92 & 0.01 & 1.19 \\
\hline & 3 & -0.03 & 1.00 & -3.19 & 0.70 & -3.81 & 0.65 & 18.54 & 7.95 & 5.69 & 1.88 \\
\hline & 4 & -0.03 & 0.95 & -0.29 & 0.56 & -0.16 & 0.73 & 0.78 & 4.75 & 0.06 & 1.12 \\
\hline & 5 & 6.77 & 1.04 & -43.42 & 0.78 & -59.68 & 0.70 & 102.36 & 1.82 & 123.80 & 2.02 \\
\hline & 6 & -0.01 & 0.99 & -0.11 & 0.77 & -0.09 & 0.81 & 0.72 & 6.43 & 0.11 & 1.30 \\
\hline & 7 & 0.04 & 1.13 & -0.16 & 0.64 & -0.18 & 0.60 & 0.58 & 5.16 & 0.04 & 1.12 \\
\hline \multirow{7}{*}{ 2010-2014 } & 1 & 0.00 & 0.98 & -0.05 & 0.60 & 0.00 & 1.00 & 0.08 & 2.01 & 0.00 & 0.98 \\
\hline & 2 & 0.00 & 1.00 & -0.04 & 0.49 & 0.00 & 1.07 & 0.04 & 1.88 & 0.02 & 1.32 \\
\hline & 3 & -0.01 & 1.00 & -3.73 & 0.69 & -3.51 & 0.71 & 21.77 & 8.44 & 8.93 & 2.40 \\
\hline & 4 & -0.04 & 0.91 & -0.33 & 0.49 & -0.23 & 0.62 & 0.86 & 6.13 & 0.03 & 1.06 \\
\hline & 5 & 11.02 & 1.05 & -66.20 & 0.73 & -69.80 & 0.72 & 133.50 & 1.87 & 187.59 & 2.40 \\
\hline & 6 & 0.13 & 1.29 & -0.15 & 0.75 & 0.04 & 1.08 & 1.12 & 9.14 & 0.19 & 1.44 \\
\hline & 7 & 0.06 & 1.14 & -0.26 & 0.55 & -0.12 & 0.76 & 0.78 & 6.25 & 0.06 & 1.15 \\
\hline
\end{tabular}

Note: Region number: 1. Mongolia and Russia region; 2. Central Asia region; 3. West Asia and North Africa region; 4. Central and Eastern region; 5. South East region; 6. South Asia region; 7. Eastern Asia region. 
(1) Mongolia and Russia

The energy structure, energy intensity and the Influence of international trade on GDP caused depressing effects, among which energy intensity played the greatest role. Per capita export goods and services trade has a significant role in increasing the $E P_{c f e c}$, and contributed the most to the $E P_{c f e c}$. The population intensity of productive land has shown a weak promotion effect, and its contribution gradually decreased.

(2) Central Asia

The energy structure, energy intensity and influence of international trade on GDP had a suppressing effect on the $E P_{c f e c}$, among which the energy intensity showed the greatest inhibition. The per capita export goods and services trade caused fluctuations. The $\triangle E P_{E P}$ was -0.01 from 1994-1999, showing the inhibition effect. During the period from 2000-2004, it was transformed into a promoting factor. During the period of 2010-2014, the $\triangle E P_{E P}$ reached 0.04 , and the rate of change was 1.88 . The intensity of productive land population always showed a promotive effect, and the effect was greater than that of the per capita export goods and services trade volume.

(3) West Asia and North Africa

The energy structure, energy intensity, and the influence of international trade on GDP inhibited the $E P_{c f e c}$ in this region. The inhibitory effect of energy intensity gradually increased, and there was little change in the energy structure. The inhibitory function of YE increased at first and then weakened. The per capita value of the trade in goods and services and the population intensity of productive land played a catalytic role. The effect of the former was greater than that of the latter, and both indicators showed an upward trend over time.

\section{(4) Central and Eastern}

The energy structure, the Influence of international trade on GDP and the energy intensity had an inhibitory effect on the $E P_{c f e c}$, with the effect is moving from small to large and increasing year by year. The per capita export goods and service trade volume, and the population intensity of productive land were both promoting effects. The former had a greater effect than the latter, and both indicators are increasing over time.

\section{(5) Southeast}

The influence of international trade on GDP had an inhibiting effect in this region. The energy structure has been transformed from inhibition to promotion, and the promotion shows an increasing trend. The energy intensity has been transformed from promotion to inhibition. The per capita exports of goods and services, the trade volume, and the population intensity of productive land still show a positive effect. The role of these factors has increased over time. The rapidly expanding population size of the region is the main reason for the promotion of the population intensity of productive land. The main reason for this is the consumption of non-renewable energy, which is the main reason for the transformation of the energy structure into a promoting effect.

\section{(6) South Asia}

Energy intensity always played an inhibitory role, and caused and increasingly strong effect year by year. The overall performance of the energy structure has increased, but the promotion effect has been relatively small, and showed a slight inhibitory effect during 2005-2009. The Influence of international trade on GDP is generally low. From 2010-2014, it began to show a small promoting effect and needs more attention. The per capita export goods and services trade volume, and the population intensity of productive land showed a promoting effect. The former is greater than the latter, and the promotion of both indicators showed an upward trend. The area is also dominated by 
primary energy consumption, which is the most important reason that the overall performance of the energy structure is the driving force.

\section{(7) Eastern Asia}

The energy intensity had a suppressing effect on the $E P_{c f e c}$ and the overall trend of suppressing effect enhanced. The influence of international trade on GDP is generally suppressed. The energy structure, the per capita export goods and service trade, and the population intensity of productive land are all contributing factors, and the impact is enhanced year by year. Among them, the per capita export of goods and services trade has the greatest promotion effect, while the energy structure and the productivity of productive land tended to be more moderate, indicating that the energy structure adjustment and productive land protection measures in the region work to good effect.

The driving effects of the various factors in the seven sub-regions are shown in Table 7.

Table 7. The effect of various factors on the regional effect.

\begin{tabular}{cccccc}
\hline Factors & ES & $\boldsymbol{E I}$ & YE & $\boldsymbol{E P}$ & $\boldsymbol{P H}$ \\
\hline Mongolia and Russia region & $\times$ & $\times$ & $\times$ & $\sqrt{ }$ & $\sqrt{ }$ \\
Central Asia region & $\times$ & $\times$ & $\times$ & $\bigcirc$ & $\sqrt{ }$ \\
West Asia and North Africa region & $\times$ & $\times$ & $\times$ & $\sqrt{ }$ & $\sqrt{ }$ \\
Central and Eastern region & $\times$ & $\times$ & $\times$ & $\sqrt{ }$ & $\sqrt{ }$ \\
South East region & $\bigcirc$ & $\bigcirc$ & $\times$ & $\sqrt{ }$ & $\sqrt{ }$ \\
South Asia region & $\bigcirc$ & $\times$ & $\bigcirc$ & $\sqrt{ }$ & $\sqrt{ }$ \\
Eastern Asia region & $\sqrt{ }$ & $\times$ & $\times$ & $\sqrt{ }$ & $\sqrt{ }$ \\
\hline
\end{tabular}

Note: $\sqrt{ }$ represents that the factor contributes to the $E P_{c f e c} ; \times$ represents the factor having an inhibitory effect on the $E P_{c f f c} ;$ and $\bigcirc$ is used to show the role of the factor changes over time.

\subsection{Discussion}

From the above research results, we can see that the ecological pressure of the carbon footprint in energy consumption is creating a serious challenge for the countries along the One Belt and One Road. Therefore, all the countries along the One Belt and One Road should pay more attention to the issue of ecological pressure, including setting clear emission reduction targets and emission reduction paths, in order to change the development model, realize green and low-carbon development, and to coordinate the balance between economic growth and environmental protection. In the future, with the aim of reducing the ecological pressure of the carbon footprint, governments should take green international trade and protecting the productive land as the primary methods, while continuing to reduce energy intensity and optimize the energy using structure (i.e., the clean energy occupying the most percentage of all the energy in the development). The green development of international trade requires all countries to strengthen cooperation and coordinate with each other, and fully consider the impact on other countries' environment in terms of export trade and capacity cooperation. These countries should fully consider their own resource endowments and regional advantages, choose a decompression route, focus on developing the domestic economy and international trade, reduce the ecological pressure of the carbon footprint, and provide new impetus for economic growth. For instance, the Mongolia and Russia region should continue to exert the inhibitory effect of the population intensity of the productive area, and Eastern Asia, South Asia, and Southeast Asia should further optimize the energy structure, increase its inhibitive influence, and reduce its effect promoting the $E P_{\text {cefc }}$. Economically underdeveloped regions, such as Central Asia, should learn from the experience of other countries by choosing green low-carbon industries as soon as possible and adopting a sustainable development model.

\section{Conclusions}

Utilizing data from the countries along the One Belt and One Road from 1994-2014, we measured the ecological pressure of the carbon footprint in energy consumption $\left(E P_{\text {cefc }}\right)$, and revealed the 
temporal and spatial dynamic changes $E P_{c e f c}$. Furthermore, by using the LMDI method to decompose its driving factors, contributions to ecological pressure arising from the carbon footprint in energy consumption was analyzed for the entire region and in seven sub-regions of the One Belt and One Road.

In general, the value of the $E P_{c e f c}$ along the One Belt and One Road increased annually as a whole. From 1994-2014, the value of the $E P_{c e f c}$ of 56 countries along the One Belt and One Road increased annually. The growth rate increased at first and then decreased, which indicates that the overall $E P_{c e f c}$ of the countries along One Belt and One Road is still high. However, the growth trend has gradually slowed down. In terms of sub-regions, the region with the most ecological stress on the carbon footprint was found to be Southeast Asia, and the lowest was Central Asia. The proportion of carbon footprint ecological pressure in Central and Eastern Europe and Mongolia was gradually decreasing over the study period. The proportion in Southeast Asia, South Asia, and China was gradually increasing, and Central Asia remains basically unchanged. The per capita export of goods and services, and the population density on productive land contribute to ecological pressure on the carbon footprint. Energy structure, the influence of international trade on GDP, and energy intensity exerted an inhibitory effect on the ecological pressure of the carbon footprint. The former had a greater effect than the latter, while the energy structure has less effect, and positive and negative fluctuations. The effect of overall per capita export of goods and services, is greater than the population intensity of productive land.

From the perspective of the seven sub-regions, the effects of various factors on the $E P_{\text {cefc }}$ are different, and the influence of each driving factor on different regions is also quite different. Energy intensity shows inhibition in all regions. During the period of 2010-2014, the inhibitory effects were as follows from small to large: Central Asia, Mongolia, Russia, South Asia, East Asia (China), Central and Eastern Europe, West Asia, North Africa and Southeast Asia. The energy structure had both inhibitory and promoting effects, but the effect was always small. Areas where it caused an inhibitory effect include Mongolia, Russia, Central Asia, West Asia, North Africa, and Central and Eastern Europe. Regions where it was a promoter include South Asia and East Asia. The impact of the Influence of international trade on GDP was generally inhibitory effect. The impact of the two factors of per capita exports of goods and services and the population intensity of productive land showed a promoting effect as a whole, and the effect of the former was greater than the latter. However, in the Mongolia-Russia region, the population intensity of productive land shows a slight increase.

This study mainly discusses issues regarding the ecological pressure of the carbon footprint in energy consumption, and other measurements of the ecological pressure of the carbon footprint from various angles, such as transportation and tourism. The conclusions of the paper can only be explained by the carbon emissions generated by energy consumption; however, this has its limitations. The regional division of land was mainly based on geography and not according to economic characteristics. The generality of the analysis conclusions is affected by this. Additionally, the productive land area conversion coefficient directly used the WWF's value to measure the carbon footprint in energy consumption without considering the difference in storage capacity of different types of productive land for carbon emissions.

Author Contributions: Q.S. established the research framework; Y.G. and F.M. jointly established the research model; C.W., B.W., X.W., and W.W. collected the data and carried out the result calculations; Q.S. provided the data acquisition channel; and Q.S. and Y.G. analyzed the results and wrote the paper together.

Funding: This study was financially supported by the National Social Science Foundation of China (grant number 17BJY139).

Conflicts of Interest: The authors declare no conflict of interest. 


\section{References}

1. Kirmani, S.; Jamil, M.; Akhtar, I. Economic feasibility of hybrid energy generation with reduced carbon emission. IET Renew. Power Gen. 2018, 12, 934-942. [CrossRef]

2. Flato, G.; Marotzke, J.; Abiodun, B.; Braconnot, P.; Chou, S.C.; Collins, W.J.; Cox, P.; Driouech, F.; Emori, S.; Eyring, V.; et al. Evaluation of climate models. In Climate Change 2013: The Physical Science Basis. Contribution of Working Group I to the Fifth Assessment Report of the Intergovernmental Panel on Climate Change; Cambridge University Press: England, UK, 2013.

3. Guan, D.B.; Klasen, S.; Hubacek, K.; Feng, K.; Liu, Z. Determinants of stagnating carbon intensity in China. Nat. Clim. Chang. 2014, 4, 1017-1023. [CrossRef]

4. Liu, Z.; Feng, K.S.; Davis, S.J.; Guan, D.; Chen, B.; Hubacek, H.; Yan, J.Y. Understanding the energy consumption and greenhouse gas emissions and the implication for achieving climate change mitigation targets. Appl. Energy 2016, 184, 737-741. [CrossRef]

5. Liu, Z.; Guan, D.; Moore, S.; Lee, H.; Su, J.; Zhang, Q. Steps to China's carbon peak. Nature 2015, 522, $279-281$. [CrossRef] [PubMed]

6. US Environmental Protection Agency. Inventory of U.S. Greenhouse Gas Emissions and Sinks: 1990-2015; Federal Register: Washington, DC, USA, 2017.

7. Cheng, Y.; Wang, Z.; Zhang, S.; Xinyue, Y.E.; Jiang, H. Spatial econometric analysis of carbon emission intensity and its driving factors from energy consumption in China. Acta Geogr. Sin. 2013, 68, 1418-1431.

8. Belkhir, L.; Elmeligi, A. Assessing ICT global emissions footprint: Trends to 2040 \& recommendations. J. Clean. Prod. 2018, 177, 448-463.

9. Song, Z.; Che, S.; Yang, Y. Topological relationship between trade network in the Belt and Road initiative area and global trade network. Prog. Geogr. 2017, 36, 1340-1348.

10. Yu, H.; Dong, S.; Li, Y.; Li, Z.; Shi, G.; Li, F.; Li, F.; Chang, Y. China's Geopolitical Strategy of the Belt and Road Initiative Based on Theory of Externality. Bull. Chin. Acad. Sci. 2016, 31, 697-706.

11. Liu, H.; Wuzhati, Y.; Wang, C. Impacts of the Belt and Road Initiative on the spatial pattern of territory development in China. Prog. Geogr. 2015, 34, 2080-2087.

12. China Think Tank Network. Available online: http://www.chinathinktanks.org.cn/ (accessed on 21 August 2014).

13. Li, G.; Yuan, Y. Impact of regional development on carbon emission: Empirical evidence across countries. Chin. Geogr. Sci. 2014, 24, 499-510. [CrossRef]

14. Wright, L.A.; Kemp, S.; Williams, I. 'Carbon footprinting': Towards a universally accepted definition. Carbon Manag. 2011, 2, 61-72. [CrossRef]

15. Galli, A.; Wiedmann, T.; Ercin, E.; Knoblauch, D.; Ewing, B.; Giljum, S. Integrating ecological, carbon and water footprint into a "Footprint Family" of indicators: Definition and role in tracking human pressure on the planet. Ecol. Indic. 2012, 16, 100-112. [CrossRef]

16. Rees, W.E. Ecological footprints and appropriated carrying capacity: What urban economics leaves out. Environ. Urban. 1992, 4, 121-130. [CrossRef]

17. Wackernagel, M. , Rees, W.E. Our Ecological Footprint: Reducing Human Impact on the Earth; New Society Publishers: Gabriola Island, BC, Canada, 1995.

18. Wackernagel, M.; Rees, W.E. Perceptual and structural barriers to investing in natural capital: Economics from an ecological footprint perspective. Ecol. Econ. 1997, 20,3-24. [CrossRef]

19. Wiedmann, T.O.; Minx, J. A definition of 'carbon footprint'. In Ecological Economics Research Trends; Nova Science Publishers: Hauppauge, NY, USA, 2008; pp. 1-11.

20. Zhao, R.Q.; Huang, X.J.; Zhong, T.Y.; Peng, J.W. Carbon footprint of different industrial spaces based on energy consumption in China. J. Geogr. Sci. 2011, 21, 285. [CrossRef]

21. Kenny, T.; Gray, N.F. Comparative performance of six carbon footprint models for use in Ireland. Environ. Impact Assess. Rev. 2009, 29, 1-6. [CrossRef]

22. Boguski, T.K. Life cycle carbon footprint of the National Geographic magazine. Int. J. Life Cycle Ass. 2010, 15, 635-643. [CrossRef]

23. Collins, F. Inclusion of carbonation during the life cycle of built and recycled concrete: influence on their carbon footprint. Int. J. Life Cycle Ass. 2010, 15, 549-556. [CrossRef] 
24. Pekala, L.M.; Tan, R.R.; Foo, D.C.Y.; Jeżowski, J.M. Optimal energy planning models with carbon footprint constraints. Appl. Energy 2010, 87, 1903-1910. [CrossRef]

25. Marriott, J.; Matthews, H.S.; Hendrickson, C.T. Impact of power generation mix on life cycle assessment and carbon footprint greenhouse gas results. J. Ind. Ecol. 2010, 14, 919-928. [CrossRef]

26. Sovacool, B.K.; Brown, M.A. Twelve metropolitan carbon footprints: A preliminary comparative global assessment. Energy Policy 2010, 38, 4856-4869. [CrossRef]

27. Cranston, G.R.; Hammond, G.P. North and south: Regional footprints on the transition pathway towards a low carbon, global economy. Appl. Energy 2010, 87, 2945-2951. [CrossRef]

28. Brown, M.A.; Southworth, F.; Sarzynski, A. The geography of metropolitan carbon footprints. Policy Soc. 2009, 27, 285-304. [CrossRef]

29. Hertwich, E.G.; Peters, G.P. Carbon footprint of nations: A global, trade-linked analysis. Environ. Sci. Technol. 2009, 43, 6414-6420. [CrossRef] [PubMed]

30. Chuai, X.W.; Lai, L.; Huang, X.J. Temporospatial changes of carbon footprint based on energy consumption in China. J. Geogr. Sci. 2012, 22, 110-124. [CrossRef]

31. Chen, C.C.; Liu, C.L.; Wang, H.; Guan, J.; Chen, L.; Wang, H.H.; Zhang, J.P.; Li, Z.; Liu, X.J. Examining the impact factors of energy consumption related carbon footprints using the STIRPAT model and PLS model in Beijing. China Environ. Sci. 2014, 34, 1622-1632.

32. Ma, F.; Wang, W.; Sun, Q.; Liu, F.; Li, X.D. Ecological pressure of carbon footprint in passenger transport: Spatio-temporal changes and regional disparities. Sustainability 2018, 10, 317.

33. Teixido-Figueras, J.; Steinberger, J.K.; Krausmann, F. International inequality of environmental pressures: Decomposition and comparative analysis. Ecol. Indic. 2016, 66, 163-173. [CrossRef]

34. Zhang, Q.; Zheng, D.; Xianshuo, X.U. Factor decomposition analysis on the energy carbon footprint ecological pressure change in China. J. Arid Land Resour. Environ. 2015, 29, 41-46.

35. Wang, S.J.; Fang, C.L.; Ma, H.T.; Wang, Y.; Qin, J. Spatial differences and multi-mechanism of carbon footprint based on GWR model in provincial China. J. Geogr. Sci. 2014, 24, 804-822. [CrossRef]

36. Feng, K.S.; Davis, S.J.; Sun, L.X.; Hubacek, K. Drivers of $\mathrm{US} \mathrm{CO}_{2}$ emissions 1997-2013. Nat. Commun. 2015, 6, 7714. [CrossRef] [PubMed]

37. Wang, S.J.; Liu, Y.Y.; Fang, C.G. Review of energy-related $\mathrm{CO}_{2}$ emission in response to climate change. Prog. Geogr. 2015, 34, 151-164.

38. Fan, Y.; Zhang, X.B.; Zhu, L. Estimating the macroeconomic cost of $\mathrm{CO}_{2}$ emission abatement in China based on multi-objective programming. Adv. Clim. Chang. Res. 2010, 6, 130-135.

39. Wang, S.J.; Fang, C.L.; Guan, X.L.; Pang, B.; Ma, H.T. Urbanization, energy consumption, and carbon dioxide emissions in China: A panel data analysis of China's provinces. Appl. Energy 2014, 136, 738-749. [CrossRef]

40. Wang, S.J.; Fang, C.L.; Wang, Y.; Ma, H.T. Quantifying the relationship between urban development intensity and carbon dioxide emissions using a panel data analysis. Ecol. Indic. 2015, 49, 121-131. [CrossRef]

41. Zhu, Y.; Li, L.F.; He, S.S.; Li, H.; Wang, Y. Peak year prediction of Shanxi Province's carbon emissions based on IPAT modeling and scenario analysis. Resour. Sci. 2016, 38, 2316-2325.

42. He, X.G.; Zhang, Y.H. Influence factors and environmental Kuznets curve relink effect of Chinese industry's carbon dioxide emission: Empirical research based on STIRPAT model with industrial dynamic panel data. China Ind. Econ. 2012, 1, 26-35.

43. Paul, S.; Bhattacharyarn, R.N. $\mathrm{CO}_{2}$ emission from energy use in India: a decomposition analysis. Energy Policy 2004, 32, 585-593. [CrossRef]

44. Fan, Y.; Liu, L.C.; Wu, G.; Tsai, H.T.; Wei, Y.M. Changes in carbon intensity in China: Empirical findings from 1980-2003. Ecol. Econ. 2007, 62, 683-691. [CrossRef]

45. Ang, B.W.; Ahang, F.Q. A survey of index decomposition analysis in energy and environmental analysis. Energy 2000, 25, 1149-1176. [CrossRef]

46. Ang, B.W. Decomposition analysis for policymaking in energy: Which is the preferred method? Energy Policy 2004, 32, 1131-1139. [CrossRef]

47. Sorrell, S.; Lehtonen, M.; Stapleton, L.; Pujol, J.; Champion, T. Decoupling of road freight energy use from economic growth in the United Kingdom. Energy Policy 2012, 41, 84-97. [CrossRef]

48. Alvydas, B.; Tomas, B.; Dalia, S. The energy intensity in Lithuania during 1995-2009: A LMDI approach. Energy Policy 2011, 39, 7322-7334. 
49. Ferdinand, V.; Ferdinand, D.; Erica, S. A decomposition analysis of $\mathrm{CO}_{2}$ emissions in the United States. Appl. Econ. Lett. 2010, 17, 925-931.

50. Yao, C.R.; Feng, K.S.; Hubacek, K. Driving forces of $\mathrm{CO}_{2}$ emissions in the G20 countries: An index decomposition analysis from 1971 to 2010. Ecol. Inform. 2014, 26, 93-100. [CrossRef]

51. Mac, S. China's changing energy intensity trend: A decomposition analysis. Energy Econ. 2008, 30, 1037-1053.

52. Zhang, M.; Liu, X.; Wang, W.; Zhou, M. Decomposition analysis of $\mathrm{CO}_{2}$ emissions from electricity generation in China. Energy Policy 2013, 52, 159-165. [CrossRef]

53. Inglesi-Lotz, R. Decomposing the south African $\mathrm{CO}_{2}$, emissions within a BRICS countries context: Signalling potential energy rebound effects. Energy 2018, 147, 648-654. [CrossRef]

54. Kopidou, D.; Tsakanikas, A.; Diakoulaki, D. Common trends and drivers of $\mathrm{CO}_{2}$, emissions and employment: A decomposition analysis in the industrial sector of selected European Union countries. J. Clean. Prod. 2016, 112, 4159-4172. [CrossRef]

55. Si, C. An Analysis of the overall pattern of China's trade cooperation with the countries along the "The Belt and Road". Reform. Strategy 2018, 34, 149-152.

56. Huang, J.B.; Liu, J.X. International production capacity cooperation of metal industry. China Popul. Resour. Environ. 2017, 27, 1-6.

57. Schott, P.K. The relative sophistication of Chinese exports. Econ. Policy 2008, 23, 5-49. [CrossRef]

58. Siggel, E. International competitiveness and comparative advantage: A survey and a proposal for measurement. J. Ind. Compet. Trade 2006, 6, 137-159. [CrossRef]

59. Everaert, G.; Heylen, F.; Schoonackers, R. Fiscal policy and TFP in the OECD: Measuring direct and indirect effects. Empir. Econ. 2015, 49, 1-36. [CrossRef]

60. Ng, E.C.Y.; Ying, C.N. What explains the total factor productivity gap between OECD economies and the U.S.? Appl. Econ. 2016, 48, 1-15. [CrossRef]

61. Byun, T.; Kim, K.; Choi, H. Comparative analysis of the total factor productivity of manufacturing in northeast Asian metropolitan areas. Growth Chang. 2012, 43, 167-177. [CrossRef]

62. Park, J. Total factor productivity growth for 12 Asian economies: The past and the future. Jpn. World Econ. 2012, 24, 114-127. [CrossRef]

63. Puskarova, P. Analysis of impacts human capital on the total factor productivity in the EU regions using the spatial Durbin model. Politicka Ekon. 2015, 63, 658-673.

64. Puskarova, P.; Piribauer, P. The impact of knowledge spillovers on total factor productivity revisited: New evidence from selected European capital region. Econ. Syst. 2016, 40, 335-344. [CrossRef]

65. Huang, J.W. Analysis of carbon footprint based on energy utilization in Hubei province. Adv. Environ. Prot. 2013, 3, 56-64.

66. IPCC Report of Climate Change. Available online: http://www.ipcc.ch (accessed on 12 April 2016).

67. U.S. Energy Information Administration. Available online: http:/ / www.eia.gov / (accessed on 15 June 2015).

68. The Institute of Electrical Engineers of Japan. Available online: http:/ / www.iee.jp/ (accessed on 23 July 2014).

69. The UK Energy Research Center. Available online: http:/ / www.ukerc.ac.uk/ (accessed on 27 January 2015).

70. World Wildlife Fund. Available online: http://www.wwfchina.org/ (accessed on 22 June 2014).

71. Carbon Dioxide Information Analysis Center. Global, Regional and National Fossil Fuel $\mathrm{CO}_{2}$ Emissions. Available online: http: / cdiac.ornl.gov / (accessed on 17 August 2014).

72. The World Bank. World Bank Open Data. Available online: https://data.worldbank.org/ (accessed on 23 November 2015).

(C) 2018 by the authors. Licensee MDPI, Basel, Switzerland. This article is an open access article distributed under the terms and conditions of the Creative Commons Attribution (CC BY) license (http:/ / creativecommons.org/licenses/by/4.0/). 